\title{
Smart City Ontologies and Their Applications: A Systematic Literature Review
}

\author{
Antonio De Nicola ${ }^{*,+}$ (D) and Maria Luisa Villani ${ }^{+}$(D) \\ ENEA-Centro Ricerche Casaccia, Via Anguillarese 301, 00123 Rome, Italy; marialuisa.villani@enea.it \\ * Correspondence: antonio.denicola@enea.it \\ + These authors contributed equally to this work.
}

check for updates

Citation: De Nicola, A.; Villani, M.L. Smart City Ontologies and Their Applications: A Systematic Literature Review. Sustainability 2021, 13, 5578. https://doi.org/10.3390/su13105578

Academic Editor: Wann-Ming Wey

Received: 15 April 2021

Accepted: 14 May 2021

Published: 17 May 2021

Publisher's Note: MDPI stays neutral with regard to jurisdictional claims in published maps and institutional affiliations.

Copyright: (c) 2021 by the authors. Licensee MDPI, Basel, Switzerland. This article is an open access article distributed under the terms and conditions of the Creative Commons Attribution (CC BY) license (https:// creativecommons.org/licenses/by/ $4.0 /)$.

\begin{abstract}
The increasing interconnections of city services, the explosion of available urban data, and the need for multidisciplinary analysis and decision making for city sustainability require new technological solutions to cope with such complexity. Ontologies have become viable and effective tools to practitioners for developing applications requiring data and process interoperability, big data management, and automated reasoning on knowledge. We investigate how and to what extent ontologies have been used to support smart city services and we provide a comprehensive reference on what problems have been addressed and what has been achieved so far with ontology-based applications. To this purpose, we conducted a systematic literature review finalized to presenting the ontologies, and the methods and technological systems where ontologies play a relevant role in shaping current smart cities. Based on the result of the review process, we also propose a classification of the sub-domains of the city addressed by the ontologies we found, and the research issues that have been considered so far by the scientific community. We highlight those for which semantic technologies have been mostly demonstrated to be effective to enhance the smart city concept and, finally, discuss in more details about some open problems.
\end{abstract}

Keywords: smart city; smart energy; smart home; urban planing; crisis management; smart health; smart service; sustainable city; ontology; semantic technology

\section{Introduction}

Smart city is a fuzzy concept encompassing both city services and available technological infrastructures that enable them [1]. A smart city is a complex cyber-socio-technical system [2] where humans, cyber artifacts, and technical systems interact together to the purpose of achieving a goal related to the quality of life in urban areas. This system is empowered by services for monitoring and awareness building on the status of the city by sensing anthropic and environmental phenomena, such as traffic and weather conditions, and by analyzing and integrating the collected data. Furthermore, technological services devoted to fulfilling the needs of citizens and protecting their lives are also emerging, concerning, for instance, environmental and critical infrastructures protection, public safety, and economic activities. According to [3], a precondition for building a smart city is the construction of sectorial applications, which encompass the construction of wireless infrastructures, smart home, smart transportation, smart public services, social management, smart urban management, smart medical treatment, green city, and smart tourism. An alternative conceptual view of a smart city is proposed by Chourabi et al. [4], which propose to focus on success factors dealing with management and organization, technology, governance, policy context, people and communities, economics, built infrastructure, and natural environment.

The interlinking between the smart city concept and available technologies have been treated by several surveys and systematic literature reviews from different perspectives. Among them, we cite works studying smart cites from the big data management perspective [5-7], those from the perspective of smart city services and platforms [8,9], those from 
the artificial intelligence applications perspective [10-12], and those from more specific applications such as recommender systems [1] and risk management [13].

According to Silva et al. [14], sustainability is among the challenges for a practical implementation of a smart city as it links to better quality of life. In particular, a sustainable city has the ability to uphold the balance of ecosystem with, respectively, infrastructure and governance, energy and climate change, pollution and waste, and, finally, social issues, economics and health. To achieve it, decision makers need to cope with the complexity and variety of available urban knowledge and data by leveraging tools aware of the interdependencies between the above mentioned city aspects.

The focus of our study is on development and usage of ontologies to build shared awareness on the various aspects of the smart city and create the ground for development of smart services, such as technologies for sustainable cities as shown by our findings. To this aim, we adopted a bottom-up approach to retrieve both works on ontologies and the smart city sectors addressed by them. An ontology is a formal explicit specification of a shared conceptualization $[15,16]$. It is a conceptual model of a part of reality, which includes interlinked concepts concerning a given application domain [17]. This is a valuable facility to cope with the smart city complexity and the related need for multidisciplinary knowledge. Initiatives to build ontologies addressing the smart city as a whole, such as the Km4City ontology [18], or for ontology catalogues [19,20], are indeed some relevant steps on this objective. However, the system-of-systems view of the smart city hinders the possibility of having a unique and complete ontology to cover the various technological and application-specific needs. Moreover, during our analysis, we realized that various sectorial ontologies have been built, but several of them are not publicly available as artifacts, or they are not maintained over time (e.g., some of those linked by [19]). Furthermore, our work demonstrates that there was a need for a rigorous study: which ontologies are in place to be used currently, what knowledge the ontologies presented in the papers represent, and what types of ontology applications described by the research community enable the improvement of smart city services.

More specifically, the aim of the present work is to answer the following research questions by means of a systematic literature review. (RQ1) To which smart city sectors ontologies, semantic methods, and semantic technologies have been applied to date? (RQ2) For which technological areas ontologies, semantic methods, and semantic technologies provide an added value? (RQ3) For each of the above mentioned sectors, which are the issues faced, and the most relevant ontologies, semantic methods, and semantic technologies used? (RQ4) To which smart city sectors semantic technologies have been mostly applied?

The systematic literature review was performed according to a process consisting of three phases: planning and design, papers gathering and semantic analysis, and takeways. The first phase aims at defining the objectives of the review, the scope of the analysis, and the steps to be performed. The second phase aims at defining the steps required to automatically and manually analyse information on papers retrieved by the SCOPUS database. The last phase concerns answering the above mentioned research questions and reporting the main findings.

The main observation following the result of the literature analysis is that technological innovation contributes to enhancement of the smart city concept but it also opens new challenges and opportunities. Although several ontologies, projects, and applications have been already developed, especially for some sectors, they do not provide full solutions to the problems they address. Furthermore, as the smart city concept is evolving from both societal and technological perspectives, there is continuous room for up-to-date semantics-enabled applications to support decision making and smart city services.

The rest of the paper is organized as follows. Section 2 provides a detailed description of the systematic literature review process. Section 3 presents the outcome of the analysis structured according to the identified smart city sectors. The answers to the research ques- 
tions are summarized in Section 4. Finally, Section 5 provides conclusions and highlights some research problems for the developers of smart city ontologies and applications.

Furthermore, given the wide domain of analysis, the paper has a modular structure so that, for the convenience of the reader, the findings related to the smart city as a whole may be read independently from the in-depth sectors-based results. Accordingly, readers interested in a general overview of smart cities ontologies and their semantic applications may focus on Sections 1 and 4; readers interested in the technical aspects concerning how this systematic literature review was performed are addressed in Section 2; and, finally, readers interested only in specific sectors (e.g., energy, or home) can read the corresponding subsections of Section 3.

\section{The Systematic Literature Review Process}

The overall aim of the systematic literature review was to identify and analyse the most relevant papers related to ontology applications for smart cities to the purpose of answering to some research questions related to the current uses of semantic technologies for smart city services and to the next challenges to be addressed (see Introduction). To this purpose, we defined a process starting from the systematic methodologies followed by the authors of existing reviews and surveys addressing smart cities, which are available in the literature $[1,5-8,10,11,13]$. The process that we defined consists of the following three phases:

- Planning \& design;

- Papers gathering \& semantic analysis;

- Takeaways.

Each phase consists of steps that were performed either automatically or by manually inspecting the collected papers.

The outline of the overall systematic literature review process is depicted in Figure 1, whereas the steps are detailed in the next subsections.

\subsection{Planning and Design}

This phase aims at defining the aim of this study and at designing a rigorous methodological approach to be followed for the review. It consists of two steps, which are described as it follows.

Define research questions. This step aims at defining the research questions for this literature review. To this purpose, the research questions that were defined have two high level purposes: analyzing and classifying previous research on applications of ontologies for smart cities and identifying relevant topics to be addressed by semantic technologies in the next future. The four research questions are presented in the Introduction and in the following text boxes.

\section{RQ1. Research question 1}

To which smart city sectors ontologies, semantic methods, and semantic technologies have been applied to date?

RQ2. Research question 2

For which technological areas ontologies, semantic methods, and semantic technologies provide an added value?

\section{RQ3. Research question 3}

For each of the above mentioned sectors, which are the issues faced, and the most relevant ontologies, semantic methods, and semantic technologies used? 


\section{RQ4. Research question 4}

To which smart city sectors semantic technologies have been mostly applied?

Design systematic literature review process. The aim of this step is to define a methodological process, which preserves the objectivity needed in automating the selection process of the scientific papers and guarantees the flexibility required to include in the analysis the relevant scientific papers that were not discovered automatically. The overall process is graphically represented as UML (Unified Modeling Language) activity diagram in Figure 1.

\subsection{Knowledge Gathering and Semantic Analysis}

This phase consists of 9 steps and has two primary goals. The former is to define the scope of the analysis by automatically collecting a set of papers from SCOPUS [21], which is the Elsevier's abstract and citation database. Our systematic literature review relies just on SCOPUS and not also on Web of Science (WoS) because the keywords available in SCOPUS are more specific than the topics available in WoS. Moreover, the coverage of SCOPUS is larger than that of WoS [22]. Furthermore, as specified later, the possible limit of SCOPUS-based only articles has been overcome in the snowballing and final selection phase. The SCOPUS database is to make a partially automated semantic analysis to classify the sectors and technological areas they address.

SCOPUS query formulation. This step provides the means to define the scope of the analysis. We identified some "seed terms" for the sectors we wanted to address and other ones for the semantic technologies. The seed terms for the sectors are: smart city, smart energy, smart home, smart transportation, smart building, and smart health. The ones for the semantic technologies are: ontology, semantics, similarity reasoning, and semantic reasoning. Then, we defined the time range for the papers. This spans the 1990-2021 year interval. The formulated query is included in the following text box.

\section{SCOPUS query}

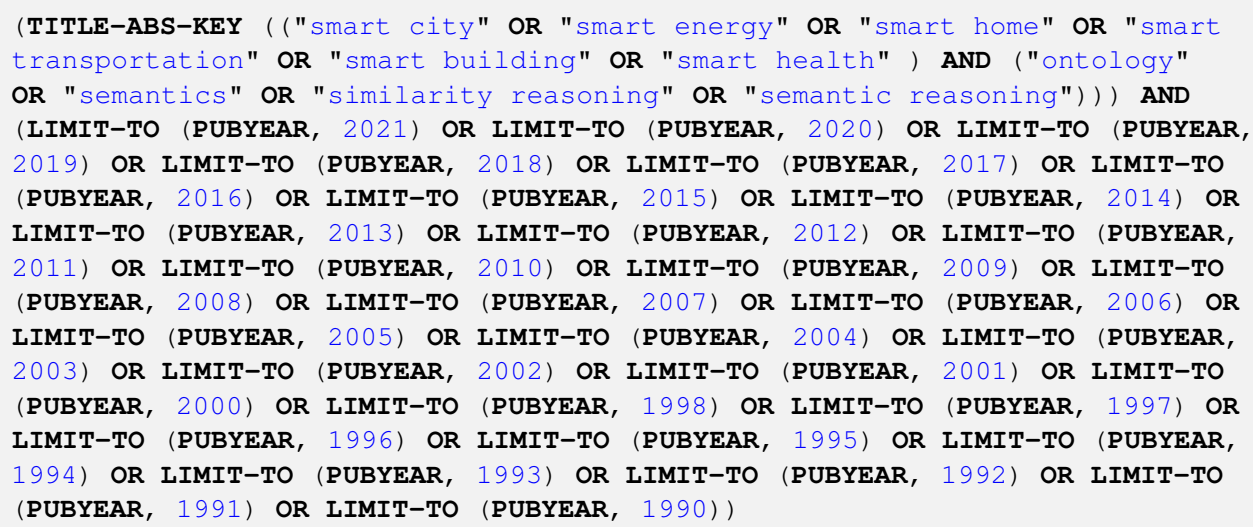

Query execution and papers retrieval. We queried the SCOPUS database on the 28 January 2021 and we retrieved 1546 papers concerning smart cities and semantic technologies. For each paper, we retrieved the authors, the title, the type of publication (i.e., journal, conference, workshop or book), the year of the publication, the number of citations, and other data as the doi, the url, the number of pages, the journal volume, and/or the journal number. Figure 2 shows the distribution of the papers by year. There is a clear cut evidence that there is an increasing interest on these topics by the scientific community. 


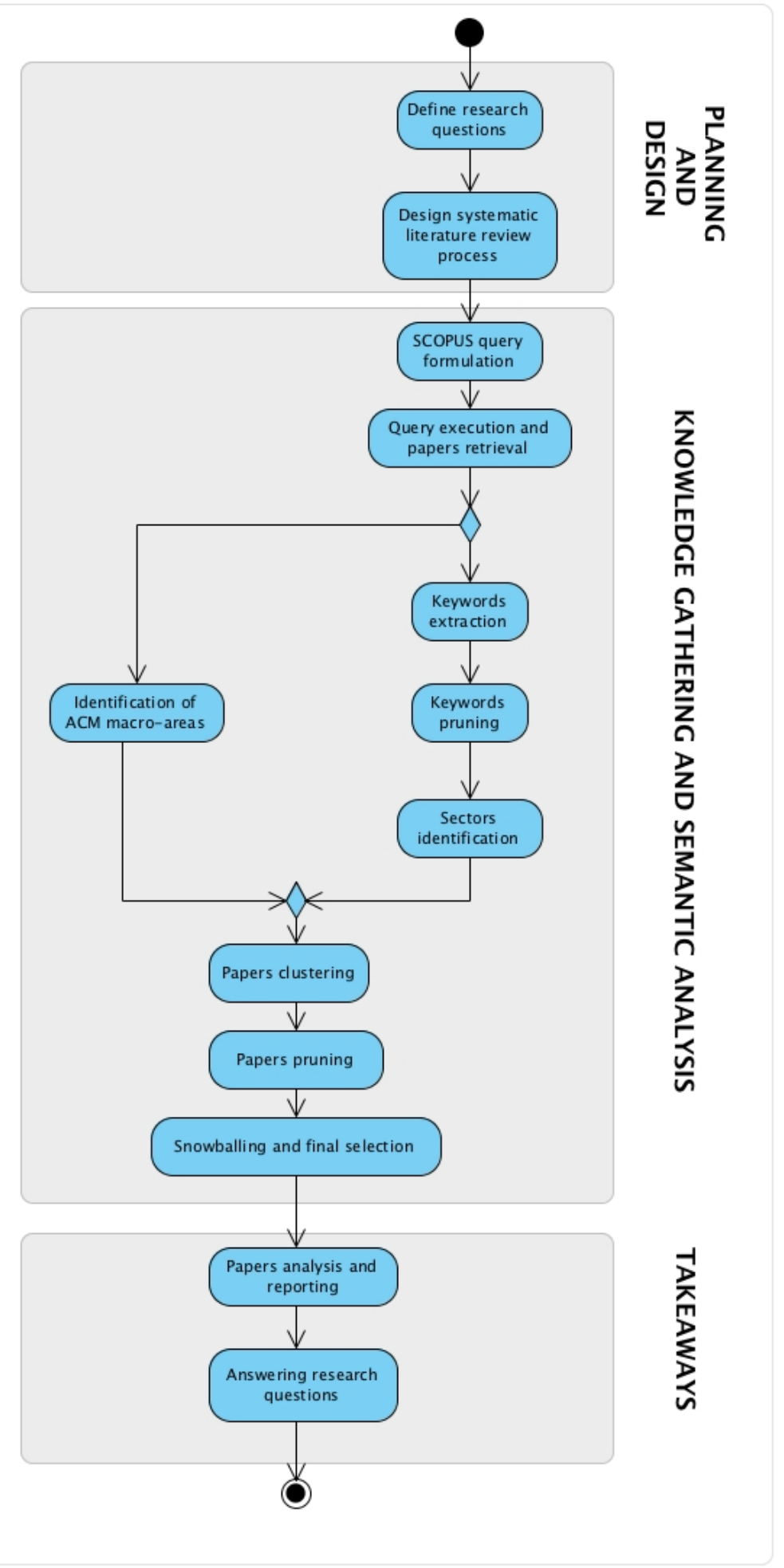

Figure 1. Systematic literature review process. 
Papers Distribution

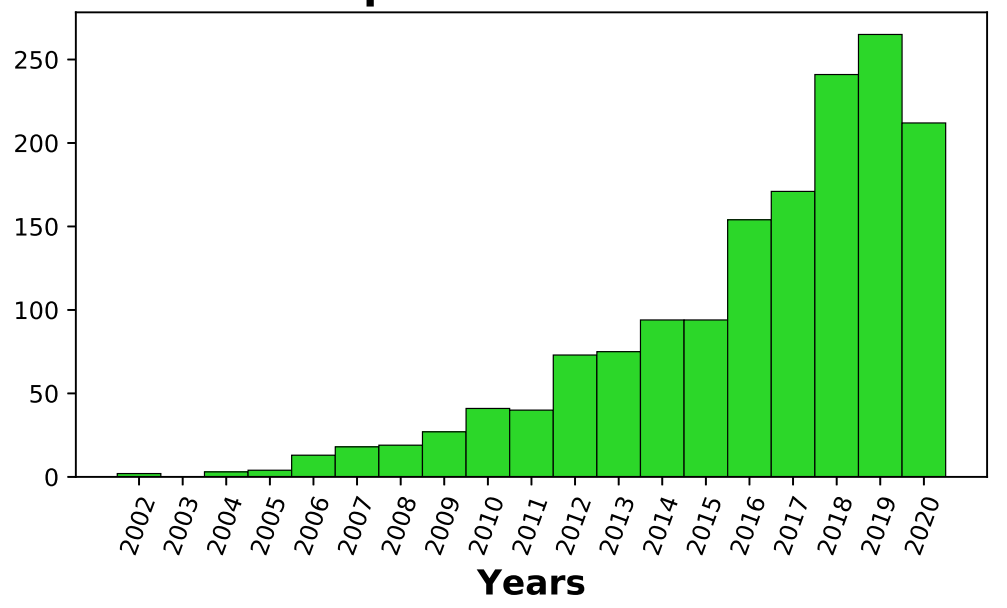

Figure 2. Distribution of retrieved papers addressing smart cities and semantic technologies by year.

Keywords extraction. In this step we extracted the keywords assigned by SCOPUS to the papers. 149 papers out of 1546 have no keywords. The overall number of keywords is 8448 , as one paper can be annotated by more than one keyword.

Keywords pruning. To the purpose of considering the most relevant topics, we considered only keywords with frequency higher than 5. After a further human-based evaluation, the resulting set consisted of 497 keywords.

Sectors identification. This step concerns the research question RQ1. We analysed the 497 keywords and we divided them in two sets. The former concerns those keywords pertaining specific smart city sectors whereas the latter concerns those related to constructs, models, methods, and technologies not depending on any specific sector. Then, we analysed the first set to the purpose of classifying the keywords in sectors. We identified the following 14 smart city sectors: communities, crisis management, eLearning, economics, energy, environment, health, home, public administration, risk management, security, social systems, sustainable development, and urban planning. A summary of these smart city sectors and the related SCOPUS keywords is presented in Figure 3 and in the Appendix A in Table A1.

Identification of ACM macro-areas. This step concerns the research question RQ2. We analysed the second set of SCOPUS keywords concerning constructs, models, methods, and technologies (see the previous step) and we classified them according to technological areas. To this purpose, we organised these keywords according to the ACM Computing Classification System (CCS) [23], which is a widely known taxonomy in the field of computer science. We classified the keywords according to the following 13 high level ACM CCS topics: applied computing, computer systems organization, computing methodologies, general purpose technology or method, hardware, human-centered computing, information systems, mathematics of computing, networks, security and privacy, social and professional topics, software and its engineering, and theory of computation. For the sake of brevity in the following, we refer to these high level ACM CCS topics as ACM macro areas. A summary of the ACM macro areas and the related SCOPUS keywords is presented in Figure 3 and in the Appendix A in Table A2.

Papers classification. In this step we classified each paper annotated with some of the selected 497 SCOPUS keywords. Indeed, we annotated a paper with a sector if it contains at least one of the corresponding SCOPUS keywords (see Table A1). In case the paper could not be annotated with any sector, we annotated it with the "virtual" sector named "other sectors". Similarly, we annotated a paper with an ACM macro area, if it contains at least one of the corresponding SCOPUS keywords (see Table A2). In case the paper could not be annotated with any ACM macro areas, we annotated it with the "virtual" area named "other methods and technologies". Following this approach, a single paper can be 
associated to more sectors and/or more ACM macro areas. A summary of the outcome of this step is shown in Figure 3.

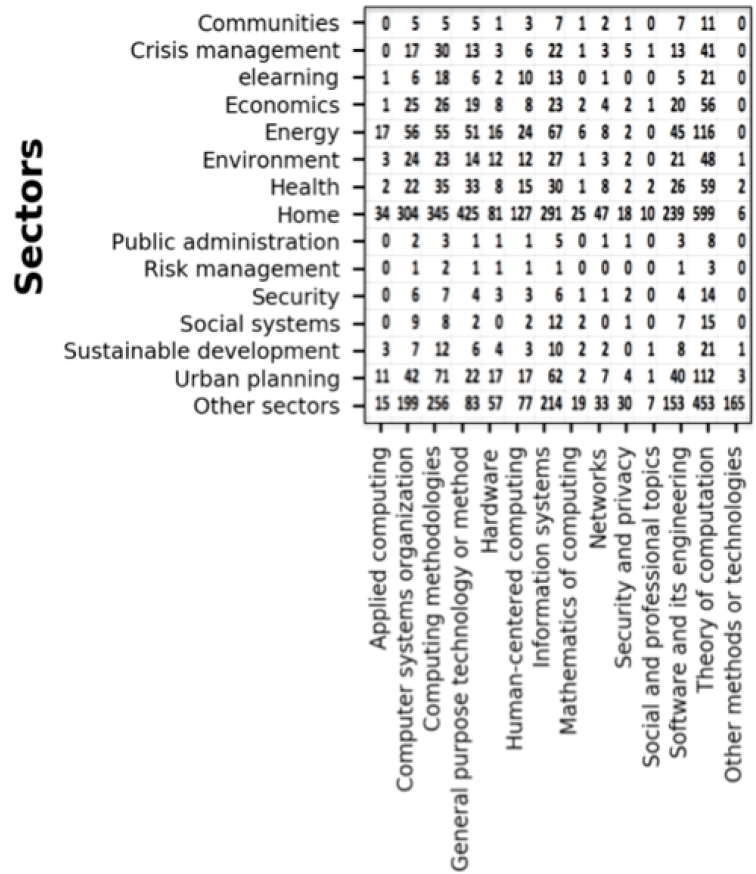

Methods and technologies

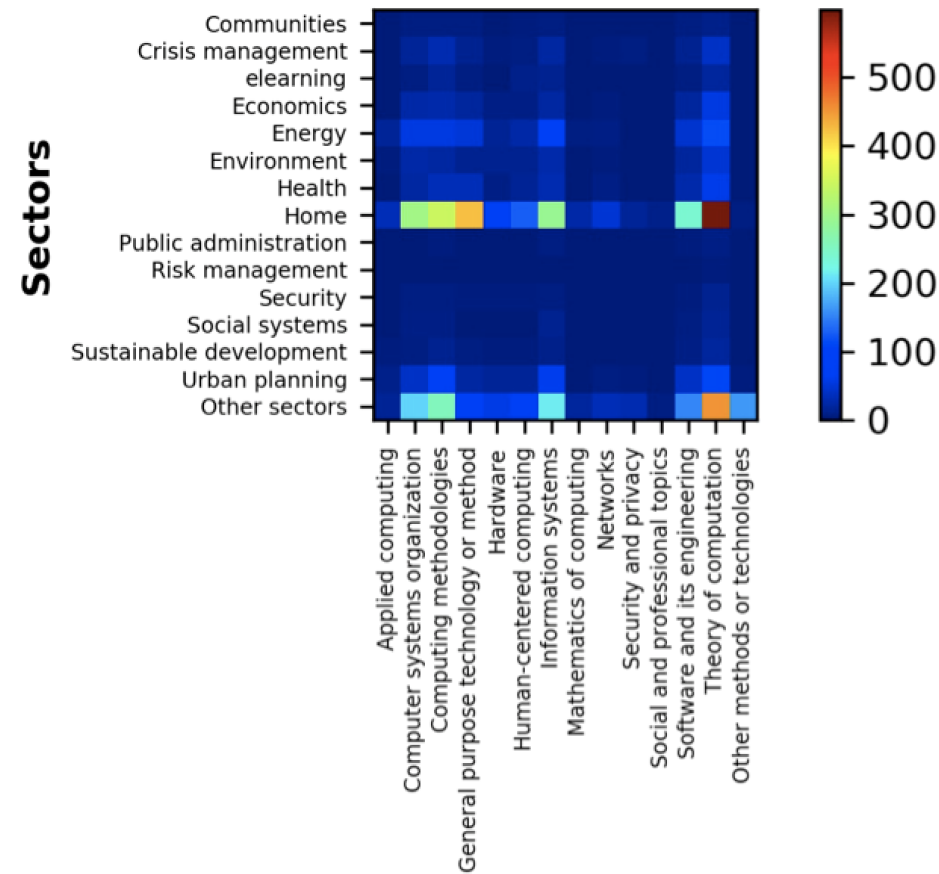

Methods and technologies

Figure 3. Summary of the outcome of the papers classification activity.

Papers pruning. This step consists in screening all the papers to the purpose of identifying the most relevant ones. To this aim, we followed several selection criteria as, for instance, the type of publication, the number of citations, and also the originality and relevance of the treated topics. In fact, journal papers or papers with an higher number of citations were assigned a higher priority during the analysis of the literature. At the end of this step, the resulting set of paper consisted of 57 papers.

Snowballing and final selection. This step consists in searching for other relevant papers that were not included in the list of papers retrieved from SCOPUS. To this purpose, we looked to the list of references of the above mentioned 57 papers and we performed tailored searches by using google scholar and ResearchGate. We followed again the same selection criteria. At the end of this step, we selected further 80 papers. Hence, the overall number of papers for this systematic literature review consisted in 137 papers.

\subsection{Takeaways}

This phase consists in a detailed analysis of the papers with the aim of answering to the three remaining research questions (i.e., RQ1, RQ2, and RQ3). It consists of two steps, which are detailed in the following.

Papers analysis and reporting. In this step we analysed in details the papers. The goal was to identify the issues, the developed ontologies, and the available services and technologies for each sector. The report of this analysis is presented in the next section.

Answering research questions. This step consists in answering to the research questions. The answers are reported in Section 4. 


\section{Sectorial Results}

The findings of the literature analysis are provided in this section. Specifically, the results for the smart city sectors are described in individual sub-sections, all with the same structure. Given a smart city sector, to answer (RQ2), the distribution of the papers in the ACM research areas is first discussed. Then, to answer (RQ3), for that application sector, we identified the issues addressed by the research works, the domain ontologies developed, and the services and technologies built by means of ontology-based approaches related to one or more of the listed issues. In particular, the described issues either refer to current research opportunities or to technological problems for which full or partial solutions are provided; the domain ontologies that have been listed either are publicly available as an artefact, or they are described in enough details in the papers; finally, the technologies and/or services refer to methods, architectures and systems that use ontologies, combined with other techniques, to reach their objectives.

The identified sectors and the related subsections are as the following: communities (see Section 3.1), crisis management (see Section 3.2), economics (see Section 3.3), eLearning (see Section 3.4), energy (see Section 3.5), environment (see Section 3.6), health (see Section 3.7), home (see Section 3.8), public administration (see Section 3.9), risk management (see Section 3.10), security (see Section 3.11), social systems (see Section 3.12), sustainable development (see Section 3.13), and urban planning (see Section 3.14).

\subsection{Communities}

We retrieved a low overall number of papers for the communities sector. Concerning the ACM macro areas, they mainly address theory of computation. This means that most of the papers addressing communities are related to topics as data and knowledge management.

\subsubsection{Issues for Communities}

Some of the most relevant papers propose solutions for supporting the creation of smart city communities. One type of community is the energy community [24]. In this domain, the following issues are described: search and retrieval of prosumers, promoting the benefits of joining a smart grid community, identification of the influencers among the prosumers community able to involve the participation of other prosumers, and acting for the community self-sustenance.

\subsubsection{Ontologies for Communities}

Maret et al. [24] present a semantically enriched data model for supporting mobile end-users in using, creating and customizing virtual communities. The data model covers four main areas: the first one addressing users, by using and extending the FOAF (Friend Of A Friend) vocabulary specification [25]; the second one addressing contents and communities by extending the SIOC (Semantically-Interlinked Online Communities) Core Ontology [26,27], which includes the main concepts and properties to describe knowledge about online communities; the third one addressing services available to users and devoted to content management; and the last one addressing goals and user roles.

\subsubsection{Services and Technologies for Communities}

Maret et al. [24] present and discuss a smart city scenario where a city makes available a community platform and provides the citizens with different web services including a ride sharing service and a question/answer service related to a train station.

Ciuciu et al. [28] present a semantically-enhanced architecture to support citizens to form communities and influence them about how they should purchase and sell energy in smart grids platforms.

\subsection{Crisis Management}

According to Figure 3, most of the papers retrieved in this literature review that address both crisis management and application of ontologies and semantic methods and 
technologies are related to the following three ACM macro areas: theory of computation, information systems and computing methodologies. This means that, in this sector, semantic technologies are mainly used to support data and knowledge management and information systems to be used in operational context. In the following we present the crisis management issues they face, some of the most relevant crisis management ontologies and some exemplary applications based on semantics.

\subsubsection{Issues for Crisis Management}

Crisis management is a complex process that encompasses activities related to a crisis event. To cope with this event, these activities are usually subdivided into phases. The most common ones are preparedness, response, recovery, and mitigation. According to out scientometric analysis, most of the works related to applications of semantic technologies in this sector mainly cover the preparedness and response phases. In the following we list the issues that we identified in the analysed papers concerning semantics-based applications for crisis management.

The first issue concerns emergency scenario design [29]. This is defined as the process of imagining crisis situations and describing them through models and stories. Emergency scenario design is usually performed in the preparedness phase.

The second issue is situational awareness that is defined as the achievement of an overall picture on a crisis, which includes the perception of elements and comprehension in the current situation and projection of future status [30].

The last issue concerns communication [31,32] and information sharing [33] during emergencies. Both are considered as relevant issues in crisis management [34].

\subsubsection{Ontologies for Crisis Management}

The Smart Cities \& Emergency Management Ontology [29] represents natural and anthropic events that could cause a crisis, impacted services and users, and human services devoted to respond to emergencies. The ontology includes 284 concepts and 117 relationships and is public [35].

The Dynamic Flood Ontology (DFO) [36] is an ontological upper model to represent the spatiotemporal changes occurring in a flood disaster situation. This can be used to make queries relevant during an urban flood scenario to the purpose of situational awareness.

POLARISCO [37] is a modular ontology addressing knowledge of French emergency responders involved in the disaster response process. The ontology consists of 8 modules related to knowledge common to the different crisis actors and knowledge, concerning respectively, firefighters, healthcare units, police ontology, gendarmerie ontology, public authorities, exchanged messages, and healthcare. POLARISCO extends the Basic Formal Ontology (BFO) [38], which is a widely adopted upper ontology. This ontology is public [39].

ResOnt is an ontology [32] that reuses existing emergency management and upper level ontologies to represent the abstract (e.g., tasks and phases) and material entities (e.g., hazardous materials) involved in an emergencies to the purpose of supporting information exchange between rescue operators.

Empathi [40] is a middle-sized ontology for emergency management and planning about hazard crises [41]. It contains 423 classes and 338 relations and includes concepts as impact, affected population, service, and volunteer support. It aims at capturing and integrating information from different sources such as satellite pictures, sensors and social media content posted by people. It imports several external vocabularies such as GeoNames [42], FOAF, LODE [43], and SIOC.

Finally, Benaben et al. [44] propose COSIMMA, a comprehensive meta-model for representing collaboration during crises. This includes a core metamodel including high level concepts related to collaboration and four packages representing, respectively, the context, the involved partners, the objective, and the behaviour. 


\subsubsection{Services and Technologies for Crisis Management}

M-CREAM $[29,45,46]$ is a web application that aims at supporting creativity in designing crisis scenarios. These are the outcome of a composition of automatically generated atomic fragments, named as mini-stories. This software leverages SPARQL [47] query processing and semantic similarity reasoning.

PROMES [33] is an ontology-based messaging service aimed at supporting information exchange in the response phase, which ensures mutual understanding among stakeholders. In PROMES, a mediator resolves terminology inconsistencies by semantically transforming messages through the POLARISCO ontology.

Hamdaoui et al. [48] propose to build multiple instances of semantic virtual spaces on top of the cloud-enabled IoT (Internet of Things) infrastructure of a smart city to increase, for instance, situational awareness during emergencies. Such semantic virtual spaces are abstractions of the IoT infrastructure that can enable different smart city applications

Rescue MODES (Medical and Operational Data Exchange System for Rescue operations) is a communication and information exchange system aimed at supporting situation awareness [32] by allowing French emergency actors involved in rescue operations to design system interfaces in a customised way [49]. To this purpose, MODES uses SPARQL queries and the ResOnt ontology.

\subsection{Economics}

The economics sector deals with all the aspects devoted to increase quality of life by improving citizens condition through new innovative services. As shown by the technical ACM macro areas (see Figure 3) that are addressed by the retrieved papers, this sector concerns also the operational aspects that enable economic transactions at the basis of smart contracts. A smart contract is a contract between agents that is completely or partially performed automatically. It is a key technology for smart cities since it allows more flexibility by avoiding the involvement of a trusted third party [50].

\subsubsection{Issues for Economics}

The issues of this sector deal with identifying new indicators to assess quality of life of citizens that go beyond GDP and enabling electronic commerce by supporting smart contracts between agents and, hence, their creation, deployment, execution, and completion [50].

\subsubsection{Ontologies for Economics}

The Global City Indicator Ontology to define how city indicators should be published in the semantic web is presented in [51]. Following this approach, a specific ontology is proposed for each of the following themes: education, shelter, health, transportation, and innovation [52].

Baracho et al. [53,54] proposed the skeleton of a comprehensive ontology for smart cities that mentions the connection of a smart city with business and industry.

The Business Innovation Ontology for smart cities [55,56] aims at representing smart city value proposition by extending the Business Model Ontology proposed by Osterwalder [57]. Value proposition describes the products and services creating value for a specific customer segment. In details, it addresses city services by proposing a service value taxonomy. This concerns: the energy sector, by including value propositions such as solar power and wind power; the living sector, by including value propositions such as coworking and services for travellers; the public and private transportation sector; and the telecommunication sector.

Smart contracts are enabled by blockchain, which is a distributed consensus system that irreversibly stores transaction data in a distributed ledger. This allows to store economic transactions of parties that do not necessarily have to trust each other. In this context, de Kruijff and Weigand [58] propose a blockchain ontology encompassing three different perspectives: the data perspective, focusing on data structures and data manipulation (e.g., 
what is a mainchain or altchain), the knowledge perspective, focusing on the conceptual level of the blockchain (e.g., what is a ledger or a transaction), and the business perspective, dealing with what is created directly or indirectly by communication (e.g., what is an economic transaction or a smart contract).

Similarly, Cantone et al. [59] extended the Ontology for Agents, Systems, and Integration of Services (OASIS) to model also smart contracts and conditionals, which allow to represent restrictions, activation mechanisms triggering agent actions, and constraints and contract terms.

\subsubsection{Semantic Services and Technologies for Economics}

Choudhury et al. [60] proposed a semantics-based service to automatically generate smart contracts starting from constraints representing blockchain requirements that are stored in ontologies and semantic rules encoded in SWRL (Semantic Web Rule Language) [61]. These are then incorporated in abstract syntax trees.

Petrović and Tošić [62] proposed a semantics-based approach to verify correctness of smart contracts by leveraging semantic annotations of the smart contract source code combined with semantic representation of domain-specific aspects, such as business logic, domain knowledge, run-time state changes and expert knowledge about vulnerabilities. The system is enabled by SPARQL query processing.

\section{4. eLearning}

This sector comprises methodological and technological approaches for education by means of IT platforms for distant learning. According to Figure 3, the papers are mostly devoted to computing methodologies, especially artificial intelligence applications to support personalized learning, human-centered computing for the aspects of user-machine communication, information systems and theory of computation, for data and knowledge modelling and management of the learning processes.

\subsubsection{Issues for eLearning}

Adaptive learning systems $[63,64]$ based on the student's profile are the most explored applications of information technology in education, where teaching methodologies are combined with new technological services, such as audio and light effects, and gamification [65] to improve engagement. Related to this issue, there are building intelligent tutoring systems [66] to support learning of students.

Diversified needs from different domains lead to development of various domain ontologies. Adult learning [64] and special needs students [67] are two examples, whereas a completely different application is e-learning to build knowledge portals for smart cities [68].

\subsubsection{Ontologies for eLearning}

The paper [69] presents ontologies for modeling goals, instructional processes and instructional materials. Specifically, IDont is a patterns-based ontological model devoted to instructional design knowledge, at a conceptual level, to map to existing learning methodologies and, at a technical level, to facilitate semi-automation of eLearning Systems. Indeed, IDont can be refined with several modular ontologies for systematic modeling of instructional design. These include: the ContextOntology, for context information and metadata related to various aspects of instructional design; the GoalsOntology, to represent learning goals or outcomes; the RolesOntology and the ProcessOntology to represent roles and the process design; the ContentOntology to model instructional material; the EvalOntology for the details of evaluation linked to the goals; the DomainOntology, to provide domain-specific version of ontology; and, finally, the EnvironmentOntology to describe the environment of the specific learning situation. 
OntoGamif $[70,71]$ is an ontology for representing the gamification domain, which includes 7 interlinked subdomains: core gamification, risk, organization, psychology, user, ethics, and evaluation.

Ontology for Gamifying Collaborative Learning Scenarios (OntoGaCLeS) [65] is devoted to supporting the personalization of game design elements in collaborative learning contexts.

\subsubsection{Services and Technologies for eLearning}

Integ-model [66] is a knowledge model, integrating ontology and frames, to build an intelligent tutoring system. This requires representing the teaching content, the user model, and the pedagogical model, which encompasses knowledge regarding various pedagogical decisions.

Smart-School Care Coordination System (SCCS) [67] is a knowledge-based system to support education, health and social care services for special needs children. The system enables coordination, integration and monitoring of the school care process to provide personalized care interventions based on a predefined care plan.

\subsection{Energy}

According to Figure 3, most of the papers retrieved in this literature review that address both energy and application of ontologies and semantic methods and technologies are related to theory of computation. This means that, in this sector, semantic technologies are mostly used to support data and knowledge management and, in particular, interoperability of data. In the following we present the energy issues these papers face, some of the most relevant energy ontologies and some exemplary applications based on semantics.

\subsubsection{Issues for Energy}

Energy is a broad sector that concerns issues from a local scale to a distributed one. In fact, among the retrieved papers, we cite papers covering both applications devoted to manage energy consumption at home and others devoted to manage energy demand response in distributed smart grids. In the following we list some of the most relevant issues that we identified in the retrieved papers.

The first issue concerns managing energy devices in smart homes [72,73] and, hence, ensuring their interoperability, scheduling home appliances in modes and times to optimize energy efficiency and take into account consumer comfort, and monitoring and controlling start and stop and the status of energy appliances.

The second issue is related to creating a community of prosumers [72,73] by supporting, for instance, negotiation for energy trading, balancing between demand and supply, or how to react to special requests from the smart grid to consume more or less due to energy availability or emergency situations, such as those, for instance, requiring temporary reduction of the power consumption.

\subsubsection{Ontologies for Energy}

The Energy Knowledge Graph (EKG) is an upper ontology model for smart energy services proposed by Chun et al. [72]. It consists of an integrated conceptual model, a modular ontology for representing microgrids, and a classification of services related to microgrid scenarios. According to [74] "a microgrid is a group of interconnected loads and distributed energy resources with defined electrical boundaries forming a local electric power system at distribution voltage levels, that acts as a single controllable entity and is able to operate in either grid-connected or island mode". The integrated conceptual model includes the following 8 concepts: smart grid entity, resource, service, process, event, smart grid participant, community, and devices). The modular ontology related to the microgrid represents its components as well as their mutual relationships. Finally, the services are classified according to their usage in either business or technical scenarios. Examples of business 
scenarios are those concerning energy trading, while examples of technical ones are those related to demand/supply management.

The Generic Ontology of Energy Consumption Households concerns a household micro-system from the energy consumption perspective [75]. This ontology includes concepts related to equipment consuming electrical energy (e.g., air conditioners and televisions), equipment producing electrical energy (e.g., photovoltaic system and wind turbine), and energy storage (e.g., lithium batteries). Finally, it describes how users are connected to home appliances and the latter to energy consumption.

PowerOnt [76] is an ontology that represents power consumption of electrical devices and appliances in smart homes. PowerOnt is integrated with DogOnt [77], which is a more general ontology for smart environments.

The SESAME ontology [78] consists of three main modules. The first one includes concepts related to automation and energy, the second one aims at representing meter data, and the third one addresses pricing.

The DEHEMS ontology [79] is the outcome of a European Union (EU) funded initiative, which aimed at increasing the usage of energy consumption data and the efficiency of energy consumption. The ontology aims at being the reference for a shared classification of devices by associating a set of recommendation for the users of electrical appliances (e.g., washing machine, personal computer), which are organized as a taxonomy. Among the properties of the electrical appliances, we cite the "energy saving tips", "EU energy label class", "wattage", "energy consumed", and "energy star", which classifies the energy efficiency of a device.

The ThinkHome ontology [80] is a comprehensive ontology encompassing seven subdomains. The energy part of the ontology gathers knowledge related to energy providers and their trading conditions. The part on exterior influences includes knowledge related to weather and climate that can be used for performing tasks more efficiently from an energy perspective. The actor part contains knowledge about groups of human and system users. The building part of the ontology gathers knowledge about layouts, spaces, walls, and materials. The process part includes knowledge about user and system activities. The resource part includes knowledge about white and brown goods and automation networks. Finally, the ontology contains also knowledge related to comfort.

The Generic Ontology for Prosumer-Oriented Smart Grid [81] gathers knowledge on a smart grid and concerns: infrastructures, electrical appliances, the electrical generation system, the power storage system, weather, relevant events for the smart grid, service contracts, and the connectivity connectivity relationships between producers and consumers.

SAREF4ENER [73] is an evolution of SAREF4EE [82] and an extension of the Smart Appliance REFerence ontology (SAREF) [83,84], which is a reference ontology for achieving semantic interoperability of smart appliances. Indeed, SAREF4ENER aims at increasing interoperability and optimize energy consumption and production in demand response scenarios.

ComfOnt [85] is an ontology aimed at providing personalized comfort in homes and at scheduling daily activities. It includes knowledge concerning: the home dwellers and their needs; the appliances, sensors, and actuators used in homes; the domestic envinronment; and energy consumption and comfort preferences and regulations. It reuses the Semantic Sensor Network (SSN) ontology [86], which is a World Wide Web Consortium (W3C) ontology for sensors and actuators, and SAREF [83].

\subsubsection{Services and Technologies for Energy}

Wendel et al. [87] propose some methodologies to build semantic 3D city models starting from free and open data sources and software, such as geospatial data portals, LIDAR data, Open Street Map data, and remote sensing data. Semantic 3D city models include, among others, semantically enriched geospatial data about buildings, encompassing materials and energy consumptions, weather, environment, vegetation and semantically enriched socio demographic data. 
SMarc [88] is a Semantic Middleware architecture for enabling management of data from smart grid applications and guaranteeing their semantic interoperability. It is enabled by an inference engine, which is able to treat the information flowing by triggering actions based on semantic data associated to devices and appliances.

Tang and Ciuciu proposed the Semantic Decision Table (SDT) [89], which is a decision table enhanced with semantic technologies, to collect data from heterogeneous meters and sensors, detect smart meters, manage data from multiple autonomous physical or virtual meters, and manage energy demand and response for communities.

\subsection{Environment}

The scientific works that we retrieved dealing with semantics and environment include three different topics: air, water, and soil. As shown in Figure 3, most of the papers concern theory of computation since they treat how environment ontologies can be used for data management and knowledge representation. The other areas that are mainly addressed are: computer systems organization, since many papers deal with sensors; computing methodologies, for the rise of scientific papers dealing with machine learning and decision making; and information systems, due to the existing software applications for managing environmental complexity.

\subsubsection{Issues for Environment}

In the following we list the issues addressed by the scientific papers dealing with ontologies and semantic methods and technologies and environment.

The first issue is air quality monitoring. Sensors are the sources of air quality data. Data interoperability or data fusion are some of the problems that need to be solved for coping with the complexity of available air quality data. The second issue concern climate change policies. To conceive them, public servants need to consider several environmental variables. Complex decisions impacting on the society need to be taken and reasoning on such huge amount of multi disciplinary data goes beyond the human capabilities. The third issue concerns water quality management and, hence, the interoperability to deal with multiple sensors. The fourth issue concerns water management including, for instance, dealing with water consumption at home. The last issue concerns dealing with soil monitoring and taking complex decisions based on soil data.

\subsubsection{Ontologies for Environment}

AIR_POLLUTION_Onto [90] is an ontology for air pollution analysis and control that includes both general concepts, such as environment, industry, soil, water, wind, and weather, and more specific ones, such as air pollutant, pollution source, and emission. The ontology includes also the meteorological concepts relevant for air pollution control and analysis.

Metral et al. [91] presented some preliminary ideas on an ontology of urban planning aimed at being a bridge between the CityGML [92] specification for virtual 3D city models and an ontology of air quality models.

EREON (Ets-Related European ONtology) [93] is an ontology for representing knowledge related to the European emission trading system (Ets). It includes concepts related to the Ets context (e.g., energy, low carbon technologies), to the policy making process, and to the computational tools to build possible future scenarios.

Ahmedi et al. [94] proposed an ontology framework for water quality management that consists of four modules: the core ontology, including concepts for real-time observational water quality data; the regulations ontology, concerning permitted water parameter thresholds regulated by the authorities; the polluters ontology, representing polluters; and the water expert rules, representing if-then water expert rules.

Howell et al. [95] presented an ontology representing man-made water system concepts at the building and network levels of detail. The building part of the ontology extends widely adopted ontologies, such as SSN and SAREF. The part integrating building with 
network represents entities, such as assets, sensors, hydraulic variables, contract types, and stakeholders. The ontology is used to support interoperability of smart home applications.

The Ontology of Soil Properties and processes (OSP) [96] combines knowledge on multiple areas, such as roads, soil, buried assets, sensing to the purpose of supporting integrated decision making. The ontology describe soil properties (e.g., soil strength) and processes (e.g., soil compaction) and the mutual relationships. Soil properties are classified as physical, chemical, and spatial whereas soil processes are classified as physical, chemical, and biological.

Finally, a preliminary attempt of an ontology devoted to integrate sensor knowledge with urban gardens and green spaces is presented by Hu et al. [97].

\subsubsection{Services and Technologies for Environment}

GECkO (GEneralized Correlation analyzer of pOllution data) [98] is a data mining system aimed at discovering correlations in a large open dataset concerning air-pollution. In details, it focuses on discovering correlations among pollutant levels and traffic and climate conditions. The system uses an exploratory data mining technique named association rule mining [99] and is based on a taxonomy categorizing, for instance, pollutant concentration levels, traffic levels, meteorological values, and hourly timeslots.

AllergyLESS [100] is an intelligent recommender system aimed at reducing exposition time to allergens in smart cities by minimizing the exposure time of citizens to allergens during their walking routes. The system is based on an ontology integrating knowledge concerning risk factors, diseases and symptoms related to asthma, contaminants and weather. AllergyLESS uses support vector machines and Bayesian networks to detect and forecast high concentrations of allergens.

Camporeale et al. [93] presented some semantic services for data acquisition and for the analysis of possible future scenarios related to the European emission trading system. For instance, they allow verification of ETS data correctness, ETS data mapping between different classification schemes, or the analysis of the impact on industrial sectors of different ETS policies. According to the proposed architecture, data is kept in the existing databases aligned with the EU ETS data schema, and analysed by means of the D2RQ platform [101,102] to enable connection of the databases with the semantic model, and enactment of the semantic rules as SQL queries.

\subsection{Health}

The general aim in this sector is to improve quality and efficiency of healthcare. Furthermore, the availability and spread of smart devices for the every day life, has provided new opportunities for healthcare technological applications. From the distribution of the research papers in Figure 3, it can be noted that, other than theory of computation, covering techniques such as for data integration and semantic modelling, these papers almost equally fit into: computer systems organization, mainly for what concerns cyber-physical systems and IoT; information systems; computing methodologies; general purpose technology or method, for automation and simulations aspects; human-centered computing, for smart devices and user interaction; and software and its engineering, for development of service-oriented and real-time systems architectures.

\subsubsection{Issues for Health}

The analyzed research in this sector is especially focused on providing solutions to increase performances of medical services by enabling healthcare at home and by integrating health services with other smart applications to the purpose of safety. The first issue is to support personalized healthcare assessment from the analysis of daily life physical activities in a non-intrusive manner. This requires to facing an important technological challenge, such as how to automatically distinguish and interpret complex physical activities [103,104] and life habits [105] from simple data collected by means of 
common usage and/or lightweight medical devices. On the other hand, new technology are exploited to improving guidance and tailor physical activities [106].

The second issue is on healthcare support to patients with cognitive decline, such as attention and working memory, which is mostly due to ageing. The technological challenge here is to intercept and recognize types of cognitive decline within monitoring activities of daily living [107-109].

The third issue is enabling tele-medicine and analysis of its impact on human safety, for example at home or during work activities. If such analysis is performed at run-time, it may be used for incident prevention [110]. This type of applications requires to solving interoperability of health services with smart applications of other domains $[108,110]$.

Related to this, there is the issue concerning empowering health information from medical services with information from the home environment to the aim of more efficient healthcare. This requires development of flexible architectures where different types of medical applications may share data collected from smart home devices to perform healthspecific analysis $[103,111]$.

\subsubsection{Ontologies for Health}

The Cognitive Semantic Sensor Network (CoSSN) ontology [103,112] is built on top of the Semantic Sensor Network (SSN) ontology to describe sensor-based applications more generally devoted to Ambient Assisted Living (AAL). In particular, the aim of the ontology is to ensure semantic interoperability of the different sensors and IoT healthcare services.

The Telehealth Smart Home ontological model [108] consists of seven ontologies needed for the functioning of a health monitoring system. These ontologies describe the house where the patient lives, the person who needs care and his medical history, his/her behaviour, the equipment and other services, and decisions to apply when a critical situation or a change of habits is detected.

The Aging Neuro-Behaviour Ontology (ANBO) [107] is devoted to modelling cognitive processes, such as the start conditions, the expected results, and qualities to identify typical or atypical manifestations. The authors integrated ANBO with the Ontology SmartLab Elderly (OSLE), an ontology related to telehealth smart homes to address cognitive processes in activities of daily living and detect cognitive decline.

The Linked Health Resources (LHR) ontology [111] is an integration ontology for data supplied by heterogeneous services, such as services aligned with the HL7 FHIR standard, an health information interoperability framework, Web services, Web of Things (WoT) services, and Linked Data. This ontology allows to represent and combine data referring to health and the home environment.

The SAREF4Health [110] is an ontology for IoT-based healthcare systems that extends the Smart Applications REFerence ontology (SAREF), a standard ETSI [113] ontology for semantic integration of applications from various domains. In particular, the ontology addresses semantic interoperability of IoT-based systems for emergency notification services and its main feature is the modelling of health data expressed by time series such as ECG.

The Smart HealthCare Ontology (SHCO) [114] models health status of patients to the aim of remote monitoring. SHCO is presented as a semantic model realized by extracting health-care knowledge such as doctor-patient records, recommended diagnosis and treatment policies.

The HealthIoT [115] ontology models the semantics of devices within the internet of medical things. This ontology provides a semantic interoperability with health-care devices and information.

\subsubsection{Services and Technologies for Health}

Semantics IoT-based healthcare system [103] is an architectural framework proposed for IoT-based monitoring applications in Ambient Assisted Living (AAL), leveraging on a Semantic Message Oriented Middleware (SeMoM). The CoSSN ontology is used to semantically annotate data from a variety of heterogeneous devices, and a reasoning 
mechanism is applied on a domain ontology to support activity recognition of patients living in health clinics.

E-care@home [116] is a system for the recognition of different activities relevant for health assessment depending on the context. Health and environmental sensors are used to detect, for example, increased heart rate and pressure sensor, and this information, together with logical rules, is used to infer activity exercising.

PARCIV [104] is a technology to recognize daily life physical activities for personalized smart health assessment by using smartphone sensors. First clusters of similar activities are created based on semantic data, and then a machine learning classifier is used to identify and detect more complex activities.

Instead, the Smart Home Simulator is a technology based on virtual reality and semantics to create an environment in which an elderly user can perform a tailored physical exercise.

With similar objectives, stochastic timed automata [105] are applied to recognize sequences of activities to the aim of personalized behaviour modelling, and semantic patterns of activities of daily leaving are used in [109] to monitor elderly patients and people with cognitive deficit.

Telehealth Smart Home [108] is a AI-based system for remote assistance of patients, with the capability to identify and prevent potentially dangerous situations for their life. The system is composed of physical devices and software applications where ontologies combined with Bayesian networks are used for activity recognition and automatic learning of the life habits of the patient. Nurses, relatives and family doctors may interact with the system.

SmartFABER [117] is a sensors-based activity recognition system to detect abnormal activity routines of elderly people living at home. The method relies on knowledge-based techniques and medical models of neuroscience to detect these abnormal behaviors and show them in a dashboard for the clinicians.

\subsection{Home}

Home is the sector attracting the highest interest to experiment new technological approaches and explore development of new services, by means of semantics-based methods. Furthermore, as demonstrated by the number and distribution of the papers in Figure 3, this sector covers all types of IT research areas more than the other specific sectors. Again, theory of computation, due to data and knowledge engineering techniques, encompasses most of the papers, and so is for other software and data-related areas, such as: information systems, computing methodologies, human-centered computing and software and its engineering. However, areas more related to IT infrastructures and other physical aspects such as: computer systems organization, general purpose technology or method, hardware, networks and security and privacy are also covered. This because domotics and smart buildings are among the current interests. Finally, papers related to theoretical and scientific applications, such as human behaviour detection and prediction under uncertainty fit into mathematics of computing and applied computing.

\subsubsection{Issues for Home}

New services for home automation aim to benefit not only directly for the persons leaving in the house, but also for the external environment and the society in general.

The first issue to face for these services is context awareness built upon a IoT-based infrastructure consisting of heterogeneous devices installed at home and connected to the network $[116,118]$. The technical challenge is integration of measurement data, given that the number of connected devices is rapidly increasing, aggregation of the information and automatic interpretation of the events.

The main issue for higher level software applications is ambient intelligence, such as advanced processing of raw data acquired by the sensors and real time decision and enactment of reactions to support persons in everyday tasks [119]. This aim encompasses 
technical challenges such as data fusion, information fusion and automatic acquisition of knowledge for detection and monitoring at highest level of abstraction [120].

Activity recognition of Daily Life (ADL) has been studied since many years [121], especially for applications in home healthcare. However, the development and spread of new devices, e.g., wearable and ambient sensors, provides opportunity to filling gaps such as uncertainties due to missing sensor data [122].

Domotics and smart buildings [123,124] are other aspects for home applications. Power meters, occupancy sensors and electrical appliances may be automatically controlled with a promising impact in energy efficiency of the house [125] and home safety and security [126].

\subsubsection{Ontologies for Home}

The Human activity ontology [127] is a network of ontologies to support user modelling, smart home context modelling and ADL modeling. The last encompasses activities related to self-care and domestic tasks that are performed by the persons of the house routinely. Indeed, the capacity to perform these activities without assistance is an indicator of autonomy of elderly people.

The Smart Home Ontology [116] extends SSN and includes modules to represent physical aspects (e.g., the structure of the environment, entities in the environment) and conceptual aspects (e.g., events or observation processes) of a smart environment. This ontology can be extended by specializing it with application-specific concepts such as those pertaining activities and health of a person in the house, so providing the representational basis for a context inference process for activity recognition.

Instead, the Smart Home Ontology presented in [125] focuses on home control and energy efficiency. It consists of five ontologies to cover the individual aspects that are relevant for the proposed application. Namely, the Building ontology refers to architecture and building physics; the User information ontology refers to preferences and occupancy profiles for all inhabitants and their comfort; the Processes ontology contains the types of automatic functions such as turning on electric heating and opening windows; the Exterior ontology refers to weather and climate conditions influencing the functions; and the Energy and resource ontology addresses energy efficient building operation.

The BonSAI ontology [123] extends smart buildings representation with ambient intelligence. It includes concepts modeling functionality, such as services and operations, environmental conditions, QoS (Quality of Service) parameters, hardware, such as smart devices, users and context, such as location and rooms.

The Brick ontology [124] is a formal representation of a schema, related to Building Information Modeling (BIM), to capture the relevant information for the building engineers and facility managers about the building, the sensors installed and the data they generate. This allows development and/or usage of energy applications such as fault detection/diagnosis and other types of communication with energy providers.

\subsubsection{Services and Technologies for Home}

The Smart Home System [125] is a knowledge-base to support the operations of a multi-agent system aiming to orchestrate energy-based facilities in a house according to energy efficiency plans. The proposed strategies include the automatic choice of the environmentally-friendliest energy supplier available for delivery of some kind of energy, disconnect unnecessary equipment, and choose electricity providers based on tariffs and excess of energy during time intervals.

Polaris [128] is a framework for Probabilistic and OntoLogical Activity RecognItion in Smart-homes. By means of an ontology that models activities and the smart home infrastructure, probabilistic semantic correlations among sensor events and activities are mined using unsupervised learning. Markov logic network is the formal structure for probabilistic reasoning. 
In [119] a framework for the implementation of ambient intelligence applications using visual sensor networks is proposed. Context knowledge represented with ontologies is combined with real time video-camera data to obtain high-level interpretation of the situation by means of logical reasoning. Recognized situations allow to achieve an overall description of the scene and trigger ambient intelligence services.

A knowledge-based approach for MultiAgent (MA) collaboration for smart home is described in [120]. Specifically, an ontology and MA technologies are combined to automatically acquire semantic knowledge overcoming heterogeneity of the services. An inference algorithm runs on unordered actions and temporal property of activity to infer both continuous composite activity and personalized service in real time. The novelty is that an agent may learn the knowledge of human activity autonomously and generate knowledge, with aim to guide other agents for performing services compatible with the human activity.

\subsection{Public Administration}

This sector refers to applications to support public administration processes and to development of new public services. The research in this sector is mostly related to realization of linked open data, as the ground for new services. Therefore, not much variety of applications has been observed in the literature. According to Figure 3, theory of computation and information systems are the areas with most papers.

\subsubsection{Issues for Public Administration}

Recent works in this sectors address the problems of realization of open government data [129], such as linked open data portals, as a single point of access to open government datasets, to provide valuable means to fostering innovation, improving transparency and collaboration by promoting citizens e-participation [130]. Open city platforms for real time monitoring [131] constitute one type of service enabled by linked open data initiatives. This requires realization of semantic models to integrate heterogeneous data collected from different public sources and archives. Another technological opportunity concerns integration of IoT-based and social applications into public administration processes [132].

\subsubsection{Ontologies for Public Administration}

The Saudi Linked Open Government Data Ontology (SLOGDO) [129] is defined to provide access to public administration datasets to the purpose of transparency. They are: General Authority for Statistics, Ministry of Human Resource and Social Development, Ministry of Interior, Ministry of Civil Service, Ministry of Justice, and Twitter datasets. An application ontology is described starting from a core ontology, the Saudi Government Ontology, and developed by means of ontology design patterns.

PPROC [133] is an ontology for public procurement processes and contracts, to allow public authorities to provide online information about tenders and citizens to monitor contracts. The PPROC ontology is extensive, and indeed covers the tender, its objectives, deadlines and awardees, but also the process, from the initial contract publication to its termination.

A Knowledge Graph for Open Government Data (KG4OGD) is proposed in [134] to support extracting knowledge related to government data and enable development of smart applications. The knowledge graph consists of the GovDataset ontology, an upper level ontology describing the metadata, and the GovDomain ontology, a domain-specific ontology to represent the open government data content level.

The Smart Living Ontology (SLO) [135] models smart city indicators and relates them to city entities (e.g., buildings, streets, areas) and its topology, to temporal entities and activities in the city. Indicators are organized in hierarchies and related to different categories of users, to allow personalised urban data exploration.

The paper [130] describes an ontology for e-Participation processes to support collaboration and interoperability between various e-Participation initiatives encompassing 
both traditional government-led processes and spontaneous citizen-led e-Participation. A democratic process is defined by the mission, the key actors (persons or organizations), the execution procedure and instruments, such legislation, resources and tools, and the expected results.

\subsubsection{Services and Technologies for Public Administration}

A Knowledge Stratification Model is proposed in [136] to identify data produced by IoT devices, integrate them into administration processes, and make them accessible and comprehensible to users. Ontologies specific for each model layer are used to represent the domain knowledge and to solve technological and user interaction semantic issues.

The paper [137] describes a methodology for developing semantic data models for smart cities based on the Linked Open Data paradigm and its application to the Municipality of Catania, in Italy following the guidelines by the Agency for Digital Italy. The semantic model integrates geographic data with other data from different sources, such as data concerning the public transport, the public lighting, the state of roads, the municipal waste collection, and historical data on the urban fault reporting service. Various types of access services are provided, such as web interfaces for the citizens, and SPARQL endopoints for the developers, to freely access the data and the ontology.

\subsection{Risk Management}

There exist different classifications of smart city risks. For instance, Shayan et al. [13] classified them as organisational, social, and technological based on the city aspects they address whereas Ullah et al. as technology-related, organisational, and external environmentrelated [138]. As shown by Figure 3, most of the papers addressing ontologies and semantic technologies devoted to risk management and smart cities deal with theory of computation and, hence, to knowledge and data management.

\subsubsection{Issues for Risk Management}

The risk management sector offers two main types of issues for the community of researchers in the field of ontologies and semantic solutions. The former concerns qualitative risk assesmment and it deals with the problem of predicting likely and unlikely (i.e., black swans) risks for a city. A further level of complexity is given by the need to predict chains of risks. The latter is related to quantitatively evaluate the level of risk for an urban area depending on available contextual information.

\subsubsection{Ontologies for Risk Management}

Among the first researchers to treat these topics, we cite Provitolo et al. [139], which presented an ontology to model systems, events, and damages, and Coletti et al. [140] that presented the Vulnerability Upper Model (VUM). i.e., an upper ontology model to represent risk, threat, system stakeholder, system, severity, and vulnerability. They presented also a case study concerning vulnerabilities of water systems and tested the VUM during workshops with stakeholders. TERMINUS (TERritorial Management and INfrastructures ontology for institutional and industrial Usage) is an ontology built starting from the VUM [141] and other ontology design patterns to represent knowledge concerning city services, territory, risk and crisis management.

Mohammad et al. [142] presented an ontology for road risks, which includes concepts representing the main elements of the road scene as vehicles, pedestrians, and environment objects. This organizes risks as risks from objects, depending, e.g., on the speed of the car, environmental risks, e.g., depending on weather conditions and road environmental risks, e.g., depending on road conditions.

The Human and Ecological health Risks Ontology (HERO) [143] is an ontology, which includes knowledge on sensors, geospatial and temporal aspects, and health risks depending, for instance, on air or water quality. The ontology is at the basis of a system for automatic prediction of air quality and related health risk. 
Among the other ontologies for representing general risks, we cite the common ontology of value and risk [144].

\subsubsection{Services and Technologies for Risk Management}

WS-CREAM is a web service implementing SPARQL queries devoted to creative generation of risk mini-models, i.e., fragments of conceptual models that suggest risks that could affect socio-technical systems, starting from the above mentioned TERMINUS ontology [141]. This software application also enables semantic spatiotemporal assessment of risks in urban areas.

Mohammad et al. [142] developed a software application to assess risk based on the pedestrian behaviour in a video scene, a road risk ontology, and some inference rules specified in Semantic Web Rule Language (SWRL).

Similarly, Yang et al. [145] developed a system based on rule reasoning to determine responses to risks due to solid waste crisis. This uses Pellet [146], the inference engine available in Protégé [147], SWRL rules, a domain ontology on waste management, and information on waste crisis.

A different approach based on a domain ontology representing factors influencing flood disaster and Bayesian networks is presented in [148]. Among the above mentioned factors, the authors cited the disasters drivers (e.g., accumulated rainfall and rainfall duration), disaster formative environment (e.g., topography and river network), and disaster bearers (e.g., pipe and road density, and population density). This approach was developed starting from historical case data during the period 2010-2018 and was used to predict and evaluate the flood disaster risk in Zhengzhou City from 16 to 20 August 2019.

Coletti et al. [149] proposed an approach to generate cascading risks in interoperable socio-technical systems based on the TERMINUS ontology and SPARQL queries. Afterwards, Yu et al. [150] proposed a similar approach by means of case-based reasoning.

Finally, Wei et al. [151] presented a decision support system to predict the potential impact of a trigger with location specific data. The system is equipped with domain ontologies and a set of rules that model critical infrastructures interdependence.

\subsection{Security and Privacy}

This sector refers to methods and technologies for protection of sensitive data and for security threat intelligence. According to Figure 3, the following areas contain most papers: theory of computation, information systems, computing methodologies, and computer systems organization. Indeed, in this sector, semantic technologies are mainly used to support data and knowledge management for threat intelligence and information sharing, and data protection in IoT systems.

\subsubsection{Issues for Security and Privacy}

The availability of smart city platforms conveying various types of data to create and deliver knowledge to build smart applications, poses security and privacy issues. One is protection of indirect information, such as that derived by sensor data or video collected for different purposes, such as data from home devices used to derive personal features of the occupants [152] or different usage of video-surveillance data. Related to this issue, there is the modelling of the user consent on usage policies in the data lake [153]. More generally, due to employment of IoT systems, data can be consumed and processed at many different places, and therefore it is difficult to identify the origin, and track the changes it has experienced and who has access to it [154].

\subsubsection{Ontologies for Security and Privacy}

A privacy vulnerability ontology is discussed in [152]. The ontology aims at identifying privacy risks when processing sensor data streams, and providing awareness about specific inference and data linkage possibilities before sharing data. The ontology includes elements for data transformations, privacy risks, attacks, and the relationships among them. 
The SPECIAL usage policy language [153] is a semantic language to represent usage policies. In line with the GDPR (General Data Protection Regulation) specification, a usage policy defines a set of authorized operations on some personal data, as contact information, and financial data. The processing operations, like collection and analysis, need to refer to an objective, e.g., health or marketing, to the storage applied and duration, and to the recipients, e.g., whom data are shared with.

The DS4IoT Ontology [154] is devoted to security in IoT systems. The ontology represents the secure data, distinguishing among encrypted data, protected data and hidden data, and the access control mechanisms that impose restrictions for an authenticated party on the access to some data. The ontology is built by taking into account several other ontologies for security in IoT, including the STAC another security ontology [155], describing assets, threats and security mechanisms among other aspects, the IoT Security Evaluation Ontology (IoTSecEv) [156], and IoT-Privontology [157] for privacy protection.

\subsubsection{Services and Technologies for Security and Privacy}

The paper [126] proposes a multi-layer cloud architectural model to enable interoperation of heterogeneous IoT services for smart home. An ontology is used for data representation and handling application heterogeneity, in particular, an ontology-based security service is designed to ensure security and privacy preservation in these applications.

A blockchain-based framework for data-sharing is described in [158]. A knowledge graph is described to define the range of information that should be included in the Privacy Policy documents. The Hyperledger Fabric blockchain technology [159] is used to develop an automated access-control and audit mechanism that enforces users' data privacy policies while sharing their data with third parties.

\subsection{Social Systems}

The systematic literature review reveals that there are only few papers addressing applications of ontologies and semantic technologies to the purpose of social good. Figure 3 shows that most of the collected papers concern information systems and theory of computation and, consequently, data and knowledge management.

\subsubsection{Issues for Social Systems}

There are three main issues for the the sector social systems: fighting poverty; detecting people radicalisation in social network; and increasing social inclusion of people in the society.

Fighting poverty requires a better understanding on the poverty signals and indicators. Semantic technologies can help in representing and managing such information and provide useful reasoning services for early detection of poverty in urban areas.

Detecting people radicalisation in social network requires the availability of advanced systems able to analyse post, tweets, and other messages. Semantic technologies could serve for this purpose.

Finally, increasing social inclusion of people in the society requires advanced methods of analysis to detect, for instance, discrimination phenomena. Methods and techniques able to provide meaning to information are among the most promising ones.

\subsubsection{Ontologies for Social Systems}

Panori et al. [160] presented an approach to design an ontology for measuring multidimensional poverty at an urban scale. In particular, they identified the main areas, which are health, education, and living standards, and the related taxonomies, encompassing more specific concepts such as material deprivation, and lack of capacity to afford a meal with meat, chicken, or fish (or vegeterian equivalent).

Along this line, Nasim and Khan [161] presented an ontology to model poverty. This includes concepts such as: absence of vocational training institutes, economic situation, 
export/import Imbalance, improper hiring, lack of job opportunities, lack of startups, and unemployment.

\subsubsection{Services and Technologies for Social Systems}

Fernandez and Alani [162] presented an approach to detect online radical content based on an ontology including the terms that are linked to radicalised rhetoric. They tested it by using two different datasets, the former of tweets posted by pro-ISIS users, and the latter by "general" Twitter users. The authors demonstrate that contextual semantics can support in better discriminating radical content from content that only makes use of radical terms.

Similarly, Barhamgi et al. [163] studied the use of domain ontologies to detect the radicalisation indicators from messages and posts on social networks.

Finally, De Nicola and D'Agostino [164] addressed the topic of gender equity by presenting a study where semantic technologies are used to study gender polarisation of the language in scientific papers.

\subsection{Sustainable Development}

This sector is closely related to environment and urban planning as it refers to protection of natural resources and decision making for sustainable development of cities. According to Figure 3, most of the papers concern theory of computation since they treat how integrated ontologies of environment and policy making can be used for data management and knowledge representation. The other areas that are mainly addressed are: computing methodologies, including artificial intelligence methods for decision making; information systems, and software and its engineering referring to realization of distributed systems for this domain.

\subsubsection{Issues for Sustainable Development}

Sustainable development works encompass cross-domain objectives such as smart management of natural resources, sustainability-aware services, policy making based on scenarios for sustainable development, and sustainability assessment.

More in details, the first two issues require technology integration and semantic interoperability of applications for optimized usage of resources like domestic water consumption [95] or development of energy efficient services [165].

The third issue concerns incorporating the sustainability objective in policy and decision making, such as towards renewable energy resources [166] and industrial technologies to favour abatement of pollution [93].

The fourth issue concerns representation of metrics for sustainability assessment [167] and their (real time) evaluation $[168,169]$ to the purpose of decision making and sustainability awareness.

\subsubsection{Ontologies for Sustainable Development}

The aim of the Urban District Sustainability Assessment (UDSA) ontology [168] is to give the user insights on the impact of their actions on the sustainability indicators, criteria and themes. The ontology is addressed to applications for governmental institutions, associations, city managers, urban planners and others having a professional role in planning for sustainability to support decision-making. It is also addressed to services for citizens to raise awareness on sustainability.

The paper [169] describes an ontology for sustainability assessment built from the analysis of 44 different approaches for sustainable measurement selected from the literature. The ontology considers various dimensions of sustainability, such as: social, environmental, economic, ecological, institutional, and cultural. The domain of usage includes: supply chain, housing (energy and water), energy resources, industrial processes, tourism sector, industrial ecology, transport, waste production disposal, pollutant dispersion, greenhouse gas emission, and ecological/ecosystem health. 


\subsubsection{Services and Technologies for Sustainable Development}

The paper [95] presents a semantic framework that unifies domestic socio-technical water systems with clean and waste networks at an urban scale, to deliver value-added services for consumers and network operators. As an example, matching the availability of water to the demand for water may lead to a number of advantages: reducing energy consumption, the leakage and water evaporation, maintenance costs of the network as well as the number of alarms.

An ontology-based IoT-enabled application for waste management is presented in [170]. The ontology is application-oriented and it is finalized to semantically enrich a city dashboard to monitor the state of the waste collection process, the routes of waste trucks, and report of malfunctions and problems.

\subsection{Urban Planning}

Urban planning refers to decision making for the city, such as on infrastructures and services to citizens, promoting innovation and sustainable development. From the distribution of the research papers in Figure 3, we see that all areas are covered and that theory of computation contains the highest number of papers, with techniques for data integration and semantic modelling. Then, similar number of papers are for computing methodologies and information systems; following, computer systems organization, and software and its engineering.

\subsubsection{Issues for Urban Planning}

Urban planning for smart city encompasses approaches devoted to planning the "smart" part of the city to best integrate technological innovation with the specific urban peculiarities and historical and cultural value [171,172].

One issue is planning to improve resilience of the city, for example the adaptive capacity to climate change-related hazards or protect and react to other natural and anthropic adverse events $[141,172,173]$, and enact specific mitigation strategies, such as urban heat island mitigation strategies [174].

This encompasses decision-making and planning for various aspects of the city, including housing, mobility, economy, education, welfare and health aspects [173]. Thus, the specific issues in urban planning are mostly addressed by the works analyzed in these mentioned sectors. Indeed, effective decision making for urban planning requires an holistic analysis which is hindered by problems related to the quantity, quality, variety and/or actual availability of data and knowledge to base such decisions. Within this sector, data integration [175-177] and visualization from spatio-temporal perspectives [18,178], and crowd-sourcing information for urban planning [173] are other issues to be addressed.

Concerning planning for smart mobility, the issues concern intelligent transportation systems to improve safety and efficiency of the urban services [179-181], creating new services for citizen such as parking guidance and information [182,183], and use mobility data to support decision making [178].

\subsubsection{Ontologies for Urban Planning}

In [151], an ontology for urban infrastructure inter-asset management is presented to model assets (e.g., road, ground, cable), triggers (e.g., pipe leaking) and potential consequences (e.g., traffic disruption). The ontology aims to represent cascading social, economic and environmental effects to the aim of decision making.

An ontology devoted to Urban Heat Island Mitigation Strategies (UHIMS) is presented in [174]. Indeed, the increase of urban temperature generally impacts on energy consumption, outdoor thermal comfort, air quality, and human health. Thus, strategies are defined to face such a problem. In the ontology, UHIMS strategies are composed of: the techniques to achieve the goals of UHIMS; the urban contexts, i.e., geographic, climatic and social-economic condition for UHIMS; and the performance metrics for UHIMS performance assessment. 
The HEritage Resilience Against CLimate Events on Site (HERACLES) Ontology [172] represents knowledge in the field of cultural heritage preservation from effects of climate change. The cultural heritage concept is related to the Vulnerability and cultural heritage value concepts to describe a risk, which quantifies possible threats to the cultural heritage from the economic perspective.

In [181], an ontology for smart transportation is illustrated. This ontology has a modular structure and contains concepts to represent the various aspects of a road traffic scenarios, such as vehicles, infrastructure elements, sensors, and driver behaviors. The sensors sub-domain is based on the Semantic Sensor Network ontology (SSN) and specifies the different types of sensors used for intelligent transportation systems.

The Connected Traffic Data Ontology (CTDO) [184] represents vehicles within the traffic ecosystem. The ontology combines sensory modelling of SSN/SOSA [185] and geospatial data and is proven to efficiently store the V2X (Vehicle-to-everything) broadcast messages coming from connected vehicles.

CityGML [186] is a standard model by the Open Geospatial Consortium (OGC) for the representation and interoperability of 3D city models. In particular, CityGML focuses on the geometrical, topological, and semantic aspects of 3D city models, including buildings, vegetation objects, water bodies, and transportation facilities like streets and railways. This model provides useful semantic structures for a variety of application domains such as urban planning, indoor/outdoor pedestrian navigation, environmental simulations, cultural heritage, and facility management.

Km4City [18] is a knowledge model for the city and its services, initially based on the models of the data sets regarding Florence and Tuscany in Italy, and then enriched by using similar datasets available on other open data portals. The ontology covers seven macroaspects, five of which are city-specific, such as: administration, encompassing PA and its specifications; the street model; the point of interests, including services and activities; the local public transportation; and sensors, such as those installed in the streets and on moving vehicles. The other two aspects deal with modelling of time and of metadata.

In [187], some Ontology Design Patterns (ODP) are proposed to support semantic modelling of various aspects of a city. In particular, these patterns are devoted to modelling: the administrative area, such as the jurisdiction purpose of a place; the city (physical) objects, including buildings, transports and devices; the events; the Key Performance Indicators (KPI)s to monitor the performance of a city (e.g., noise or pollution data, recycling rate, etc.); the measurements, including those to evaluate KPIs; the public services, such as waste management, public parking, and water quality control; and the topology of the city. These ODPs are the outcome of a systematic analysis of the literature that takes into account ontologies and data models addressing specific aspects of a smart city, including GeoSPARQL, CityGML [186], Km4City [18]. Thus, the ODPs result from an abstraction work of the various modelling solutions.

\subsubsection{Services and Technologies for Urban Planning}

The proposed semantics-based approaches for decision making to the purpose of urban planning include models and technologies to enable data/information collection by means of participatory processes, supported by gamification [173], or platforms for the ingestion of public and private data for smart city, including open data from public administration and private data coming from transport systems [18]. Along this line, a framework for citizen-related big data analysis to support governance decision-making is proposed in [188]. The framework uses ontology models to standardize urban governance-related attributes, personas, and associations using data mining and Bayesian networks techniques. 
The paper [189] presents 3cixty, a framework to building a knowledge base that contains descriptions of events and activities, places and monuments, transportation facilities as well as social activities of a city. The development of an information service for tourists visiting the city for a big event, such as Expo, is discussed as an application, which leverages on the KM4City ontology and collects data from static, near- and real-time local and global data providers.

Intelligent transportation and automation are addressed in various works. To provide some examples, in [190], a specific instance of IoE (Internet of Everything) for driver-less vehicle(s) is proposed. The framework uses reasoning upon ontologies, and learning technologies to enrich the formal model of the $\mathrm{IoE}$ and to assist the vehicle in driving decisions. Semantic interoperability of smart city IoT applications for development of smart urban mobility services is addressed in [181] to improve safety on road by supplying traffic information, and in [183] with the aim to provide parking guidance and mobility suggestions. Finally, in [180] context representation, ontology and Bayesian networks are used to analyse data from various sensors in an urban area in order to predict the bicycle-sharing public service usage in the city of London.

The paper [191] describes the Smart City Service System, a knowledge based system to support the decision-making processes of a city. The knowledge base extends Km4City with EventOntology [192] to represent events with more details and with technology oriented ontologies such as OWL-S, to support the description of services, and SSN to extend the representation of sensors and sensor data. The integrated information is analyzed to provide situation-awareness of the city by means of inference and classification processes. This allows the governors, policymakers, and decision-makers to identify trends that can help predict future situations and to make coherent and informed decisions for improving the smart city, thus offering new services and realizing innovative projects.

\section{Discussion}

In this section we answer the research questions presented in the introduction.

(RQ1) To which smart city sectors ontologies, semantic methods, and semantic technologies have been applied to date?

The results from the query to SCOPUS database led us to identify 14 sectors where ontologies, semantic methods, and semantic technologies have been applied to date. They are: communities, crisis management, e-learning, economics, energy, environment, health, home, public administration, risk management, security, social systems, sustainable development, and urban planning. A description of these sectors with the SCOPUS keywords identifying them is provided in Table A1 of the Appendix A.

(RQ2) For which technological areas ontologies, semantic methods, and semantic technologies provide an added value?

In order to detect the technological aspects addressed by the retrieved papers, we classified the papers by means of the ACM macro areas. Accordingly, ontologies, semantic methods, and semantic technologies provide value for the following ones: applied computing, computer systems organization, computing methodologies, general purpose technology or method, hardware, human-centered computing, information systems, mathematics of computing, networks, security and privacy, social and professional topics, software and its engineering, and theory of computation. A description of the ACM macroareas in terms of the SCOPUS keywords of the published papers is provided in Table A2 of the Appendix A. 
Among the identified ACM macro areas, most of the papers focus on theory of computation, which is the ACM area concerning ontologies, knowledge bases, and theoretical models for data/information representation and processing. Other relevant areas are: computing methodologies, concerning algorithms and artificial intelligence methods for analysis and process automation in the smart city context; information systems, regarding systems for data and information collection and management; computer systems organization, describing socio-cyber-physical systems, IoT and other technological architectures for distributed and embedded systems devoted to smart cities; general purpose technology or method; and software and its engineering, focusing on software architectures, service-oriented modelling, communication and integration aspects (see Figure 3).

(RQ3) For each of the above mentioned sectors, which are the issues faced, and the most relevant ontologies, semantic methods, and semantic technologies used?

We listed the most relevant ontologies, semantic methods, and semantic technologies used to date in Section 3. Altogether, we have described 67 ontologies and 50 among methods and applications leveraging semantic technologies. We identified 56 issues, which are summarised in Table 1. A cross-domain issue is data interoperability to enable automatic collection from heterogeneous systems and devices. This lays the foundation towards objectives such as interdisciplinary knowledge building and representation, knowledgebased situation awareness at various levels of granularity, and actionable knowledge.

\section{(RQ4) To which smart city sectors semantic technologies have been mostly applied?}

Among the identified sectors, most of the efforts of the research communities focus on the home sector, the energy sector, and the urban planning sector. Indeed, the widespread of low-cost sensor devices allows easy and scoped experimentation of novel approaches for smart home and energy efficiency. On other hand, smart transportation is of high interest for urban planning due to the technological challenges to improve safety and efficiency of the urban services and as means for sustainability goals. Furthermore, the availability of structured and unstructured data about the city, directly collected and crowdsourced or indirectly deduced from automatic processing and reasoning, provides a huge opportunity to urban knowledge building and development of semantic services to support decision-making for the city.

Other relevant sectors for the semantic technologies are the health, environment, and economics sectors (see Figure 3). These are the sectors where more traditionally ontologies have been proposed, especially for development of expert systems and business process automation. However, the introduction and widespread of new technologies like IoT, cloud infrastructures and blockchain poses new interesting challenges. These include solutions for tele-medicine and new healthcare support, quality monitoring of natural resources to support decision making at local level or governmental policies to mitigate effects of climate change, and smart contracts adoption to improve efficiency of business processes and enhance their dematerialization.

Table 1. Summary of the research issues for the smart city sectors.

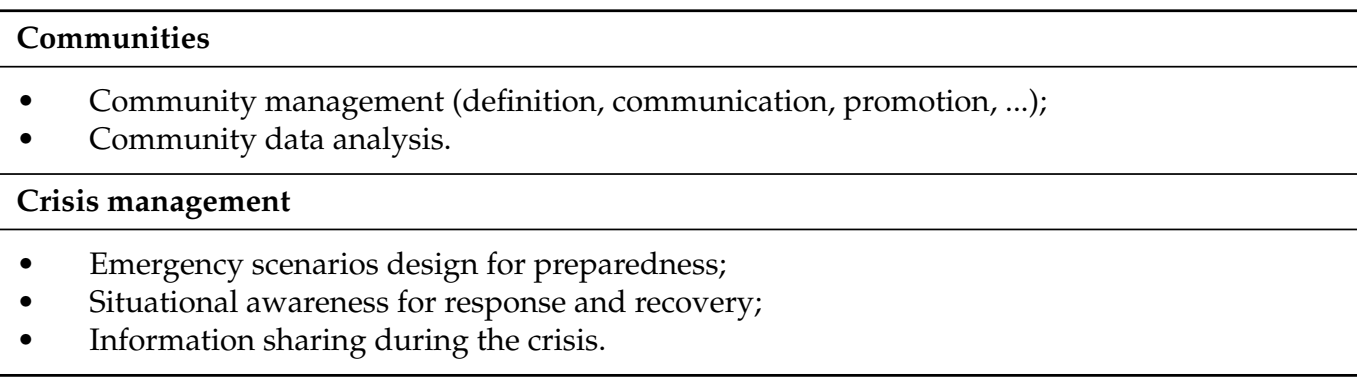


Table 1. Cont.

\section{eLearning}

- Adaptive learning based on students profiles;

- Intelligent tutoring;

- Gamified learning;

- $\quad$ Adult learning and special needs student education;

- Education on new topics such as smart city knowledge.

\section{Economics}

- Definition of new indicators for the economy of a smart city;

- Management of smart contracts.

\section{Energy}

- Management of energy consumption in smart homes;

- Smart energy services;

- Management of energy demand/response in distributed smart grids;

- $\quad$ Energy costs trading.

\section{Environment}

- Data interoperability and fusion for monitoring the environment (air, soil, water);

- Pollution awareness and services for reduction and protection;

- Definition of policies for climate change;

- $\quad$ Services to optimize consumption of natural resources, such as water.

\section{Health}

- Data interoperability and fusion to support healthcare at home;

- Tele-medicine;

- Health assessment integrating medical records with physical activity data;

- Healthcare support to patients with cognitive decline;

- Integration of health services with other smart applications to the purpose of safety.

\section{Home}

- Data interoperability and fusion for context awareness in smart home;

- Activity recognition of Daily Life (ADL);

- Ambient intelligence services;

- Domotics and smart buildings.

\section{Public administration}

- $\quad$ Open Government Data, such as linked open data portals;

- Citizens e-participation to decision making;

- Integration of IoT-based and social applications into public administration processes;

- $\quad$ Open city platforms for real time monitoring of public services.

\section{Risk management}

- $\quad$ Risk identification and qualitative assessment;

- Cascading risk representations and analysis;

- Contextual data analysis for quantitative risk assessment.

\section{Security and privacy}

- $\quad$ Protection of indirect information, e.g., derived from sensor data or video;

- Modelling user consent to data usage policies;

- $\quad$ Backtracking data and access control;

- $\quad$ Security in IoT systems. 
Table 1. Cont.



\section{Conclusions}

The increasing complexity of smart cities requires new methods and technologies to address the issues of an urban area and to conceive and implement new innovative services for citizens.

One basic issue to sustain such development is the actual knowledge of how the smart city is conceived now, what technologies have contributed to shaping its concept, and what the current challenges for further development are. Ontologies for smart cities are certainly a viable means to providing such answers as they reflect the current knowledge and contribute to building new knowledge when used for data harmonization, interoperability, and semantic analysis of ground data and information.

To this purpose, by using a systematic literature review process, we investigated how and to what extent ontologies have been used to support smart city services. Specifically, we reviewed 137 papers presenting 67 ontologies and 50 among methods and applications leveraging semantic technologies. We identified 56 issues in different smart city sectors, which we deeply discussed. In particular, the described issues refer to current problems for which full or partial solutions have been provided so far, and the technologies and/or services refer to methods, architectures and systems that use ontologies, combined with other techniques, to reach their objectives. Furthermore, a classification of the reviewed papers for each sector, that has been automatically created based on the SCOPUS keywords and ACM macro-areas, provides a detailed understanding on this last aspect.

The outcome of our analysis is a comprehensive and up-to-date reference on the various problems being addressed by the research community and the results achieved. In particular, as result of our analysis, we highlighted some relevant issues, and open problems, addressed in the sectors with the highest interest.

Author Contributions: These authors contributed equally to this work. All authors have read and agreed to the published version of the manuscript.

Funding: This research received no external funding.

Institutional Review Board Statement: Not applicable.

Informed Consent Statement: Not applicable. 
Data Availability Statement: Not applicable.

Conflicts of Interest: The authors declare no conflict of interest.

\section{Abbreviations}

The following abbreviations are used in this manuscript:

$\begin{array}{ll}\text { AAL } & \text { Ambient Assisted Living } \\ \text { ACM } & \text { Association for Computing Machinery } \\ \text { ADL } & \text { Activity recognition of Daily Life } \\ \text { BFO } & \text { Basic Formal Ontology } \\ \text { BIM } & \text { Building Information Modeling } \\ \text { CCS } & \text { Computing Classification System } \\ \text { ETS } & \text { Emission Trading System } \\ \text { FOAF } & \text { Friend Of A Friend } \\ \text { GDP } & \text { Gross Domestic Product } \\ \text { GDPR } & \text { General Data Protection Regulation } \\ \text { IoT } & \text { Internet of Things } \\ \text { KPI } & \text { Key Performance Indicator } \\ \text { MA } & \text { MultiAgent } \\ \text { ODP } & \text { Ontology Design Pattern } \\ \text { OGC } & \text { Open Geospatial Consortium } \\ \text { OWL } & \text { Web Ontology Language } \\ \text { QoS } & \text { Quality of Service } \\ \text { SDT } & \text { Semantic Decision Table } \\ \text { SPARQL } & \text { SPARQL Protocol and RDF Query Language } \\ \text { SQL } & \text { Structured Query Language } \\ \text { SSN } & \text { Semantic Sensor Network ontology } \\ \text { SWRL } & \text { Semantic Web Rule Language } \\ \text { UML } & \text { Unified Modeling Language } \\ \text { V2X } & \text { Vehicle-to-everything } \\ \text { W3C } & \text { World Wide Web Consortium } \\ \text { WoT } & \text { Web of Thing } \\ & \end{array}$

\section{Appendix A}

The appendix presents a summary of the smart city sectors and related SCOPUS keywords and a summary of the ACM macro areas and the related SCOPUS keywords.

Table A1. Summary of the smart city sectors and related SCOPUS keywords.

\begin{tabular}{ll}
\hline Smart City Sector & SCOPUS Keywords \\
\hline Communities & Communities. \\
\hline Crisis management & Situation awareness, accidents, monitoring, disasters. \\
\hline eLearning & e-learning, student, engineering education. \\
\hline Economics & Electronic commerce, economics, economic and social effects, quality of life, innovation. \\
\hline Energy & $\begin{array}{l}\text { Energy conservation, energy management, smart-grids, distributed energy resources, } \\
\text { energy-efficiency, energy resource, energy management systems, smart energy, renewable energy } \\
\text { resources, energy utilization, electric power transmission networks, smart power grids, energy policy. }\end{array}$ \\
\hline Environment & Ecology, air quality, forestry, environmental monitoring, ecosystems, birds. \\
\hline Health & $\begin{array}{l}\text { Physiological models, smart health, mhealth, diagnosis, ambient assisted living (aal), health, health } \\
\text { monitoring, health risks, ehealth, patient monitoring, medical computing. }\end{array}$ \\
\hline
\end{tabular}


Table A1. Cont.

\begin{tabular}{ll}
\hline Smart City Sector & SCOPUS Keywords \\
\hline & $\begin{array}{l}\text { Building management systems, indoor positioning systems, smart environment, ambient assisted } \\
\text { living, human activity, smart-home, home network, smart device, building information model - bim, } \\
\text { building management, smart home technology, daily life activities, home health care, building } \\
\text { automation, domestic appliances, attention mechanism., housing, smart buildings, built environment, } \\
\text { residential homes, activities of daily living (adls), behavioral research, brick, smart space, bim, } \\
\text { assistive living, surrounding environment, activity of daily livings, human activity recognition, home } \\
\text { services, ambient intelligence systems, smart appliances, building information modeling, building, } \\
\text { home automation, office buildings, building automation systems, activity recognition, intelligent } \\
\text { buildings, ambient intelligent, smart-home system, home automation systems, activity modeling, } \\
\text { home environment. }\end{array}$ \\
\hline Public administration & $\begin{array}{l}\text { Public administration. } \\
\text { Risk management }\end{array}$ \\
\hline Security & Risk management, risk assessment. \\
\hline Social systems & Security. \\
\hline Sustainable development & Social media, social systems. \\
\hline Sustainable development. \\
\hline $\begin{array}{l}\text { Planning, intelligent transport systems, transportation, waste management, smart mobility, crime, } \\
\text { motor transportation, urban transport, smart parking, vehicles, urban planning, roads and streets, } \\
\text { transportation system, traffic congestion, trajectory, traffic signs, sanitary sewers, traffic control, } \\
\text { urban growth, intelligent vehicle highway systems. }\end{array}$ \\
\hline
\end{tabular}

Table A2. Summary of the ACM macro areas and the related SCOPUS keywords.

\begin{tabular}{ll}
\hline ACM Macro Areas & SCOPUS Keywords \\
\hline Applied computing & forecasting, green computing, telecommunication services, metadata. \\
\hline & smart object, cyber physical systems (cpss), sensors and actuators, internet-of-things, heterogeneous \\
& systems, cybernetics, pervasive environment, pervasive computing, sensors data, wireless networks, \\
& cyber-physical systems, actuators, real time systems, internet of thing (iots), ubiquitous environment, \\
& iot service, heterogeneous sensors, sensor nodes, wireless sensor networks, sensor, web of things, \\
Computer systems & semantic sensors, sensors network, iot, gateways (computer networks), pervasive systems, iot \\
organization & applications, real-time, cyber-physical-social systems, remote sensing, ubiquitous computing, cloud \\
& computing, robot, reference architectures, fog computing, complex event processing, radio frequency \\
& identification (rfid), semantic sensor network, embedded systems \\
\hline
\end{tabular}

deep neural networks, text mining, image segmentation, abstracting, automata theory, speech recognition, learning systems, feature extraction, mobile computing, knowledge management, video recording, knowledge based, context reasoning, topic modeling, conceptual framework, distributed computing systems, image classification, knowledge engines, image processing, decision making, knowledge-based systems, clustering algorithms, three dimensional computer graphics, knowledge graphs, intelligent agents, commonsense knowledge, anomaly detection, adaptive systems, deep learning, cameras, blockchain, multi-agent system, modeling languages, extraction, trees (mathematics), bayesian networks, decision making process, context aware service, machine learning

Computing methodologies techniques, clusters, knowledge representation, artificial intelligence, computer aided design, conceptual modeling, classification, context-aware system, natural language process, context-aware computing, video signal processing, linguistics, cognitive systems, multi agents, case-based reasoning, modelling, edge computing, context ontology, autonomous agents, neural networks, computational linguistics, real-time, learning algorithms, concurrent activities, transfer learning, text processing, convolutional neural networks, domain knowledge, long short-term memory, pattern recognition, adaptability, object detection, uncertainty, knowledge model, image analysis, machine learning, classification (of information), hierarchical systems, uncertainty analysis, syntactics, latent semantic analysis, natural language processing systems, software agents, intelligent computing, supervised learning, cluster analysis, context aware applications. 
Table A2. Cont.

\begin{tabular}{|c|c|}
\hline ACM Macro Areas & SCOPUS Keywords \\
\hline $\begin{array}{l}\text { General purpose } \\
\text { technology or method }\end{array}$ & $\begin{array}{l}\text { simulator, computational platforms, engineering, quality control, technology, information and } \\
\text { communication technology, management, methodology, computer science, internet, technological } \\
\text { solution, automation, computer simulation, iterative methods, information technology, algorithm, } \\
\text { mathematical models, time series, websites, life cycle, computer, markup languages, runtime, software. }\end{array}$ \\
\hline Hardware & $\begin{array}{l}\text { computer architecture, internet of thing (iots), digital devices, computer circuits, memory architecture, } \\
\text { distributed systems. }\end{array}$ \\
\hline $\begin{array}{l}\text { Human-centered } \\
\text { computing }\end{array}$ & $\begin{array}{l}\text { human-computer interaction, social networking online, mobile computing, social network, mobile } \\
\text { devices, user models, mobile telecommunication systems, visualization, } 3 \mathrm{~d} \text { modelling, user experience, } \\
\text { social sciences computing, virtual reality, human robot interaction, flow visualization, } 5 \mathrm{~g} \text { mobile } \\
\text { communication systems, citygml, wireless telecommunication systems, user interfaces, interactive } \\
\text { computer systems, digital twin, edge computing, computer-vision, user interaction, communications } \\
\text { technology, graphical methods, smartphones, virtualizations, user profiling, augmented reality, mobile } \\
\text { applications, man machine systems, graphical user interfaces. }\end{array}$ \\
\hline Information systems & $\begin{array}{l}\text { Conceptual modeling, control system, abstracting, social networking online, knowledge management, } \\
\text { decision support, conceptual framework, information use, sentiment analysis, knowledge based, topic } \\
\text { modeling, modeling languages, location-based services, information science, knowledge-based } \\
\text { systems, context information, clustering algorithms, knowledge graphs, gis, recommendation systems, } \\
\text { personal communication systems, social sciences computing, personalizations, information } \\
\text { management, intelligent systems, crowdsourcing, classification (of information), trees (mathematics), } \\
\text { information services, contextual information, knowledge representation, information exchanges, } \\
\text { metadata, geographical information system, classification, knowledge engines, personalized services, } \\
\text { scalability, decision support systems, information system, modelling, intelligent services, clusters, } \\
\text { information retrieval, information model, domain knowledge, world wide web, commonsense } \\
\text { knowledge, expert system, information dissemination, information analysis, uncertainty, knowledge } \\
\text { model, collective intelligence, intelligent environment, hierarchical systems, uncertainty analysis, } \\
\text { location information, multimedia systems, cluster analysis. }\end{array}$ \\
\hline $\begin{array}{l}\text { Mathematics of } \\
\text { computing }\end{array}$ & $\begin{array}{l}\text { Graph theory, information theory, error analysis, markov processes, statistics, hidden markov model, } \\
\text { topology }\end{array}$ \\
\hline Networks & $\begin{array}{l}\text { World wide web, internet protocols, social networking online, complex networks, network architecture, } \\
\text { topology. }\end{array}$ \\
\hline Security and privacy & Trusted computing, network security, access control. \\
\hline $\begin{array}{l}\text { Social and professional } \\
\text { topics }\end{array}$ & System analysis, systems engineering. \\
\hline $\begin{array}{l}\text { Software and its } \\
\text { engineering }\end{array}$ & $\begin{array}{l}\text { soa, requirement engineering, control system, abstracting, service compositions, heterogeneous data, } \\
\text { software design, service-oriented architecture, interoperations, topic modeling, conceptual framework, } \\
\text { computer program, service discovery, electronic data interchange, service, computer programming } \\
\text { languages, computer software reusability, software architecture, cloud services, integration, modeling } \\
\text { languages, services and applications, service-oriented, service oriented architecture (soa), web services, } \\
\text { software prototyping, description languages, computer software, conceptual modeling, quality of } \\
\text { service, specifications, heterogeneous data sources, design and implements, mapping, modelling, } \\
\text { heterogeneous devices, open source software, heterogeneous information, real-time, software } \\
\text { engineering, architectural design, reusability, standardization, heterogeneous sources, } \\
\text { machine-to-machine communication, service modeling, middleware, software applications, system } \\
\text { architecture, architecture, seamless integration, design. }\end{array}$ \\
\hline
\end{tabular}


Table A2. Cont.

\begin{tabular}{ll}
\hline ACM Macro Areas & SCOPUS Keywords \\
\hline & semantic network, social network, semantic data, data sets, data stream, large amounts of data, \\
& semantic interpretation, reasoning, big data, data exploration, modeling languages, ontology \\
alignment, linked-data, semantic descriptions, word embeddings, data modeling, semantic & analysis, data acquisition, distributed database systems, query languages, semantic segmentation, \\
& ontology approach, data fusion, ontological models, search engines, data analytics, ontology \\
& development, context model, data handling, semantic rules, ontological engineering, topic \\
& modeling, semantic technologies, descriptions logics, ontology-based context, semantic matching, \\
& computation theory, -linked-open-data, formal specification, linked open datum, model check, \\
& open datum, semantic representation, embeddings, semantic features, data-driven approaches, \\
& data structures, large dataset, predictability, semantic processing, rdf, query processing, linked \\
& datum, semantic information, data integration, owl, web ontology language, database systems, \\
& social networking online, conceptual framework, data mining, semantic web technologies, fuzzy \\
& sets, decision making, semantic web rule language (swrl), semantic enrichment, semantic \\
knowledge, decision tree, data heterogeneity, semantic ontology, decision making process, & advanced analytics, semantic interoperability, ontologies, data management, data sourcing, \\
Theory of computation & conceptual modeling, context reasoning, semantic similarity, heterogeneous data sources, semantic \\
& reasoner, semantic services, modelling, data processing, fuzzy logic, data collection, data \\
& visualization, data warehouses, domain ontology, probabilistic logics, data aggregators, \\
& optimization, digital storage, real-world datasets, abstracting, ontology reasoning, temporal logic, \\
semantic web, formal languages, ontology representations, ontological frameworks, data sharing, & -semantic, data interoperability, heterogeneous data, data communication systems, graph databases, \\
semantic models, ontology-based, data privacy, semantic annotations, semantic approach, \\
commonsense knowledge, sparql, open data, semantic integration, resource description framework, \\
data description, formal methods, protege.
\end{tabular}

\section{References}

1. Quijano-Sánchez, L.; Cantador, I.; Cortés-Cediel, M.E.; Gil, O. Recommender systems for smart cities. Inf. Syst. 2020, 92, 101545. [CrossRef]

2. Patriarca, R.; Falegnami, A.; Costantino, F.; Di Gravio, G.; De Nicola, A.; Villani, M.L. WAx: An integrated conceptual framework for the analysis of Cyber-Socio-Technical Systems. Saf. Sci. 2021, 136, 105-142. [CrossRef]

3. Su, K.; Li, J.; Fu, H. Smart city and the applications. In Proceedings of the 2011 International Conference on Electronics, Communications and Control (ICECC), Ningbo, China, 9-11 September 2011; pp. 1028-1031. [CrossRef]

4. Chourabi, H.; Nam, T.; Walker, S.; Gil-Garcia, J.R.; Mellouli, S.; Nahon, K.; Pardo, T.A.; Scholl, H.J. Understanding Smart Cities: An Integrative Framework. In Proceedings of the 2012 45th Hawaii International Conference on System Sciences (HICSS'12), Maui, HI, USA, 4-7 January 2012; pp. 2289-2297. [CrossRef]

5. Moustaka, V.; Vakali, A.; Anthopoulos, L.G. A Systematic Review for Smart City Data Analytics. ACM Comput. Surv. $2018,51$. [CrossRef]

6. Usman, M.; Jan, M.A.; He, X.; Chen, J. A Survey on Big Multimedia Data Processing and Management in Smart Cities. ACM Comput. Surv. 2019, 52. [CrossRef]

7. Habibzadeh, H.; Kaptan, C.; Soyata, T.; Kantarci, B.; Boukerche, A. Smart City System Design: A Comprehensive Study of the Application and Data Planes. ACM Comput. Surv. 2019, 52. [CrossRef]

8. Perera, C.; Qin, Y.; Estrella, J.C.; Reiff-Marganiec, S.; Vasilakos, A.V. Fog Computing for Sustainable Smart Cities: A Survey. ACM Comput. Surv. 2017, 50. [CrossRef]

9. Santana, E.F.Z.; Chaves, A.P.; Gerosa, M.A.; Kon, F.; Milojicic, D.S. Software Platforms for Smart Cities: Concepts, Requirements, Challenges, and a Unified Reference Architecture. ACM Comput. Surv. 2017, 50. [CrossRef]

10. Bhattacharya, S.; Somayaji, S.R.K.; Gadekallu, T.R.; Alazab, M.; Maddikunta, P.K.R. A review on deep learning for future smart cities. Internet Technol. Lett. 2020, e187. [CrossRef]

11. Yigitcanlar, T.; Desouza, K.C.; Butler, L.; Roozkhosh, F. Contributions and Risks of Artificial Intelligence (AI) in Building Smarter Cities: Insights from a Systematic Review of the Literature. Energies 2020, 13, 1473. [CrossRef]

12. Yigitcanlar, T.; Butler, L.; Windle, E.; Desouza, K.C.; Mehmood, R.; Corchado, J.M. Can Building "Artificially Intelligent Cities" Safeguard Humanity from Natural Disasters, Pandemics, and Other Catastrophes? An Urban Scholar's Perspective. Sensors 2020, 20, 2988. [CrossRef]

13. Shayan, S.; Kim, K.P.; Ma, T.; Nguyen, T.H.D. The First Two Decades of Smart City Research from a Risk Perspective. Sustainability 2020, 12, 9280. [CrossRef]

14. Silva, B.N.; Khan, M.; Han, K. Towards sustainable smart cities: A review of trends, architectures, components, and open challenges in smart cities. Sustain. Cities Soc. 2018, 38, 697-713. [CrossRef] 
15. Gruber, T.R. A translation approach to portable ontology specifications. Knowl. Acquis. 1993, 5, 199-220. [CrossRef]

16. Borst, W.N. Construction of Engineering Ontologies for Knowledge Sharing and Reuse. Ph.D. Thesis, University of Twente, Enschede, The Netherlands, 1997.

17. De Nicola, A.; Missikoff, M. A Lightweight Methodology for Rapid Ontology Engineering. Commun. ACM 2016, 59, 79-86. [CrossRef]

18. Bellini, P.; Benigni, M.; Billero, R.; Nesi, P.; Rauch, N. Km4City ontology building vs data harvesting and cleaning for smart-city services. J. Vis. Lang. Comput. 2014, 25, 827-839.

19. Gyrard, A.; Zimmermann, A.; Sheth, A. Building IoT-Based Applications for Smart Cities: How Can Ontology Catalogs Help? IEEE Internet Things J. 2018, 5, 3978-3990. [CrossRef]

20. READY4SmartCities Website. Available online: http:/ / smartcity.linkeddata.es/ (accessed on 15 May 2021).

21. SCOPUS Website. Available online: https://www.scopus.com (accessed on 15 May 2021).

22. Singh, V.; Singh, P.; Karmakar, M.; Leta, J.; Mayr, P. The journal coverage of Web of Science, Scopus and Dimensions: A comparative analysis. Scientometrics 2021. [CrossRef]

23. ACM Computing Classification System. Available online: https: / d dlacm.org/ccs (accessed on 15 May 2021).

24. Maret, P.; Laforest, F.; Lanquetin, D. A semantic web model for Ad Hoc context-aware virtual communities application to the smart place scenario. In Proceedings of the 16th International Conference on Enterprise Information Systems (ICEIS), Lisbon, Portugal, 27-30 April 2014; Volume 2, pp. 591-598.

25. Graves, M.; Constabaris, A.; Brickley, D. Foaf: Connecting people on the semantic web. Cat. Classif. Q. 2007, 43, 191-202. [CrossRef]

26. Breslin, J.G.; Decker, S.; Harth, A.; Bojars, U. SIOC: An approach to connect web-based communities. Int. J. Web Based Commun. 2006, 2, 133-142. [CrossRef]

27. SIOC (Semantically-Interlinked Online Communities) Core Ontology. Available online: http://rdfs.org/sioc/spec/ (accessed on 15 May 2021).

28. Ciuciu, I.; Meersman, R.; Dillon, T. Social network of smart-metered homes and SMEs for grid-based renewable energy exchange. In Proceedings of the 2012 6th IEEE International Conference on Digital Ecosystems and Technologies (DEST), Campione d'Italia, Italy, 18-20 June 2012. [CrossRef]

29. De Nicola, A.; Melchiori, M.; Villani, M.L. Creative Design of Emergency Management Scenarios Driven by Semantics: An Application to Smart Cities. Inf. Syst. 2019, 81, 21-48. [CrossRef]

30. Endsley, M.R. Toward a Theory of Situation Awareness in Dynamic Systems. Hum. Factors 1995, 37, 32-64. [CrossRef]

31. Sermet, Y.; Demir, I. An intelligent system on knowledge generation and communication about flooding. Environ. Model. Softw. 2018, 108, 51-60. [CrossRef]

32. Chehade, S.; Matta, N.; Pothin, J.B.; Cogranne, R. Handling effective communication to support awareness in rescue operations. J. Contingencies Crisis Manag. 2020, 28, 307-323. [CrossRef]

33. Elmhadhbi, L.; Karray, M.H.; Archimède, B.; Otte, J.N.; Smith, B. PROMES: An ontology-based messaging service for semantically interoperable information exchange during disaster response. J. Contingencies Crisis Manag. 2020, 28, 324-338. [CrossRef]

34. Van de Walle, B.; Brugghemans, B.; Comes, T. Improving situation awareness in crisis response teams: An experimental analysis of enriched information and centralized coordination. Int. J. Hum. Comput. Stud. 2016, 95, 66-79. [CrossRef]

35. Smart Cities \& Emergency Management Ontology. Available online: http://tinyurl.com/crisismng4-0 (accessed on 15 May 2021).

36. Kurte, K.; Potnis, A.; Durbha, S. Semantics-enabled spatio-temporal modeling of earth observation data: An application to flood monitoring. In Proceedings of the 2nd ACM SIGSPATIAL International Workshop on Advances on Resilient and Intelligent Cities, Chicago, IL, USA, 5 November 2019; pp. 41-50. [CrossRef]

37. Elmhadhbi, L.; Karray, M.H.; Archimède, B. A modular ontology for semantically enhanced interoperability in operational disaster response. In Proceedings of the 16th International Conference on Information Systems for Crisis Response and Management-ISCRAM 2019, Valencia, Spain, 19-22 May 2019; pp. 1021-1029.

38. Arp, R.; Smith, B.; Spear, A.D. Building Ontologies with Basic Formal Ontology; The MIT Press: Cambridge, MA, USA, 2015.

39. POLARISCO Ontology. Available online: https://github.com/LindaElmhadhbi/POLARISCO (accessed on 15 May 2021).

40. Empathi Ontology. Available online: https://shekarpour.github.io/empathi.io (accessed on 15 May 2021).

41. Gaur, M.; Shekarpour, S.; Gyrard, A.; Sheth, A. Empathi: An Ontology for Emergency Managing and Planning about Hazard Crisis. In Proceedings of the 2019 IEEE 13th International Conference on Semantic Computing (ICSC), Newport Beach, CA, USA, 30 Januanry-1 February 2019; pp. 396-403. [CrossRef]

42. GeoNames Ontology. Available online: http:/ /www.geonames.org/ontology (accessed on 15 May 2021).

43. LODE Ontology. Available online: http://linkedevents.org/ontology (accessed on 15 May 2021).

44. Benaben, F.; Fertier, A.; Montarnal, A.; Mu, W.; Jiang, Z.; Truptil, S.; Barthe-Delanoë, A.M.; Lauras, M.; Mace-Ramete, G.; Wang, T.; et al. An AI framework and a metamodel for collaborative situations: Application to crisis management contexts. J. Contingencies Crisis Manag. 2020, 28, 291-306. [CrossRef] 
45. De Nicola, A.; Melchiori, M.; Villani, M.L. M-CREAM: A Tool for Creative Modelling of Emergency Scenarios in Smart Cities. In The Semantic Web: ESWC 2018 Satellite Events; Gangemi, A., Gentile, A.L., Nuzzolese, A.G., Rudolph, S., Maleshkova, M., Paulheim, H., Pan, J.Z., Alam, M., Eds.; Lecture Notes in Computer Science; Springer International Publishing: Cham, Switzerland, 2018; Volume 11155, pp. 83-88.

46. M-CREAM Website. Available online: https://sites.google.com/view/m-cream (accessed on 15 May 2021).

47. Pérez, J.; Arenas, M.; Gutierrez, C. Semantics and complexity of SPARQL. ACM Trans. Database Syst. (TODS) 2009, 34, 1-45. [CrossRef]

48. Hamdaoui, B.; Alkalbani, M.; Znati, T.; Rayes, A. Unleashing the Power of Participatory IoT with Blockchains for Increased Safety and Situation Awareness of Smart Cities. IEEE Netw. 2020, 34, 202-209. [CrossRef]

49. Chehade, S.; Matta, N.; Pothin, J.B.; Cogranne, R. Ontology-Based Approach for Designing User Interfaces: Application for Rescue Actors. In Proceedings of the ISCRAM 2020 Conference Proceedings-17th International Conference on Information Systems for Crisis Response and Management, Blacksburg, VA, USA, 24-27 May 2020; pp. 54-65.

50. Zheng, Z.; Xie, S.; Dai, H.N.; Chen, W.; Chen, X.; Weng, J.; Imran, M. An overview on smart contracts: Challenges, advances and platforms. Future Gener. Comput. Syst. 2020, 105, 475-491. [CrossRef]

51. Forde, A.N.; Fox, M.S. Residency and service towards a standard for representing telecommunications and innovation open data. Int. J. Innov. Learn. 2017, 22, 407-423. [CrossRef]

52. Fox, M.S. The role of ontologies in publishing and analyzing city indicators. Comput. Environ. Urban Syst. 2015, 54, 266-279. [CrossRef]

53. Baracho, R.M.A.; Soergel, D.; Pereira Junior, M.; Henriques, M. A Proposal for Developing a Comprehensive Ontology for Smart Cities/Smart Buildings/Smart Life. In Proceedings of the 10th International Multi-Conference on Complexity, Informatics and Cybernetics, Orlando, FL, USA, 12-15 March 2019; pp. 110-115.

54. Baracho, R.; Soergel, D.; Mullarkey, M. Toward a Comprehensive Smart Ecosystem Ontology a Smart Cities, Smart Buildings, Smart Life. J. Syst. Cybern. Inform. 2020, 18, 25.

55. De Nicola, A.; Vicoli, G.; Villani, M.L. Gamified Software to Support the Design of Business Innovation. Information 2018, 9 , 324. [CrossRef]

56. Business Innovation Ontology for Smart Cities. Available online: https://tinyurl.com/BIOforSmartCities (accessed on 15 May 2021).

57. Osterwalder, A. The Business Model Ontology a Proposition in a Design Science Approach. Ph.D. Thesis, Université de Lausanne, Faculté des Hautes études Commerciales, Lausanne, Switzerland, 2004.

58. de Kruijff, J.; Weigand, H. Understanding the Blockchain Using Enterprise Ontology. In Advanced Information Systems Engineering; Dubois, E., Pohl, K., Eds.; Springer International Publishing: Cham, Switzeland, 2017; pp. $29-43$.

59. Cantone, D.; Longo, C.F.; Nicolosi-Asmundo, M.; Santamaria, D.F.; Santoro, C. Ontological Smart Contracts in OASIS: Ontology for Agents, Systems, and Integration of Services. arXiv 2020, arXiv:2012.01410.

60. Choudhury, O.; Rudolph, N.; Sylla, I.; Fairoza, N.; Das, A. Auto-Generation of Smart Contracts from Domain-Specific Ontologies and Semantic Rules. In Proceedings of the 2018 IEEE International Conference on Internet of Things (iThings) and IEEE Green Computing and Communications (GreenCom) and IEEE Cyber, Physical and Social Computing (CPSCom) and IEEE Smart Data (SmartData), Halifax, NS, Canada, 30 July-3 August 2018; pp. 963-970. [CrossRef]

61. Horrocks, I.; Patel-Schneider, P.F.; Boley, H.; Tabet, S.; Grosof, B.; Dean, M. SWRL: A semantic web rule language combining OWL and RuleML. W3C Memb. Submiss. 2004, 21, 1-31.

62. Petrović, N.; Tošić, M. Semantic Approach to Smart Contract Verification. Facta Univ. Ser. Autom. Control. Robot. 2020, 19, 21-37.

63. Wang, H. Application and Research of Information Technology in Art Teaching. Adv. Intell. Syst. Comput. 2021, 1303, 1646-1651. [CrossRef]

64. Abyaa, A.; Idrissi, M.K.; Bennani, S. An Adult Learner's Knowledge Model Based on Ontologies and Rule Reasoning. In Proceedings of the Mediterranean Symposium on Smart City Application; SCAMS '17; Association for Computing Machinery: New York, NY, USA, 2017. [CrossRef]

65. Challco, G.C.; Moreira, D.; Mizoguchi, R.; Isotani, S. Towards an Ontology for Gamifying Collaborative Learning Scenarios. In Intelligent Tutoring Systems; Springer International Publishing: Cham, Switzerland, 2014; Volume 8474, pp. 404-409. [CrossRef]

66. Le, T.T.; Luu, S.T.; Nguyen, H.D.; Do, N.V. Knowledge representation for designing an Intelligent Tutoring System in learning of courses about Algorithms. In Proceedings of the 2019 25th Asia-Pacific Conference on Communications (APCC), Ho Chi Minh City, Vietnam, 6-8 November 2019; pp. 310-315. [CrossRef]

67. Hafidh, R.; Sharif, M.; Al-Bayatti, A.; Alfakeeh, A.; Alassafi, M.; Alqarni, M. An effective knowledge-based modeling approach towards a "Smart-School Care Coordination system" for children and young people with special educational needs and disabilities. Symmetry 2020, 12, 1495. [CrossRef]

68. Kutzner, I.; Hauke, K.; Marciniak, K.; Owoc, M. Creation of the Urban Knowledge Portal: E-Learning and Knowledge Inventor Context. In Proceedings of the 2015 11th International Conference on Semantics, Knowledge and Grids (SKG) (SKG '15), Beijing, China, 19-21 August 2015; pp. 97-104. [CrossRef]

69. Chimalakonda, S.; Nori, K. An ontology based modeling framework for design of educational technologies. Smart Learn. Environ. 2020, 7. [CrossRef] 
70. Bouzidi, R.; De Nicola, A.; Nader, F.; Chalal, R. OntoGamif: A modular ontology for integrated gamification. Appl. Ontol. 2019, 14, 215-249. [CrossRef]

71. OntoGamif Ontology. Available online: https://data.mendeley.com/datasets/6gx487xb4c/2 (accessed on 15 May 2021).

72. Chun, S.; Jung, J.; Jin, X.; Seo, S.; Lee, K.H. Designing an integrated knowledge graph for smart energy services. J. Supercomput. 2020, 76, 8058-8085. [CrossRef]

73. Daniele, L. SAREF4ENER: An Extension of SAREF for the Energy Domain Created in Collaboration with Energy@Home and EEBus Associations; Technical Report; ETSI: Madrid, Spain, 2020. Available online https://saref.etsi.org/saref4ener/v1.1.2/ (accessed on 15 May 2021).

74. International Electrotechnical Commission. Definition of Microgrid. Available online: https://www.electropedia.org/iev/iev. nsf/display?openform\&ievref=617-04-22 (accessed on 19 March 2021).

75. Kott, J.; Kott, M. Generic ontology of energy consumption households. Energies 2019, 12, 3712. [CrossRef]

76. Bonino, D.; Corno, F.; De Russis, L. Poweront: An ontology-based approach for power consumption estimation in smart homes. In Lecture Notes of the Institute for Computer Sciences, Social-Informatics and Telecommunications Engineering, LNICST; Springer: Cham, Switzerland, 2015; Volume 150, pp. 3-8. [CrossRef]

77. Bonino, D.; Corno, F. DogOnt-Ontology Modeling for Intelligent Domotic Environments. In Proceedings of the 7th International Conference on the Semantic Web (ISWC '08), Karlsruhe, Germany, 26-30 October 2008; pp. 790-803. [CrossRef]

78. Fensel, A.; Tomic, S.; Kumar, V.; Stefanovic, M.; Aleshin, S.; Novikov, D. SESAME-S: Semantic smart home system for energy efficiency. Informatik-Spektrum 2013, 36, 46-57. [CrossRef]

79. Shah, N.; Chao, K.M.; Zlamaniec, T.; Matei, A. Ontology for Home Energy Management Domain. In Digital Information and Communication Technology and Its Applications; Cherifi, H., Zain, J.M., El-Qawasmeh, E., Eds.; Springer: Berlin/Heidelberg, Germany, 2011; pp. 337-347.

80. Reinisch, C.; Kofler, M.; Iglesias, F.; Kastner, W. ThinkHome Energy Efficiency in Future Smart Homes. EURASIP J. Embed. Syst. 2011, 2011. [CrossRef]

81. Gillani, S.; Laforest, F.; Picard, G. A Generic Ontology for Prosumer-Oriented Smart Grid. In Proceedings of the Workshops of the EDBT/ICDT 2014 Joint Conference, Athens, Greece, 28 March 2014.

82. Daniele, L.; Solanki, M.; den Hartog, F.; Roes, J. Interoperability for Smart Appliances in the IoT World. In The Semantic Web_ISWC 2016; Groth, P., Simperl, E., Gray, A., Sabou, M., Krötzsch, M., Lecue, F., Flöck, F., Gil, Y., Eds.; Springer International Publishing: Cham, Switzerland, 2016; pp. 21-29.

83. Daniele, L.; den Hartog, F.; Roes, J. Created in close interaction with the industry: The smart appliances reference (SAREF) ontology. In Proceedings of the International Workshop Formal Ontologies Meet Industries, Berlin, Germany, 5 August 2015; pp. $100-112$.

84. SAREF Ontology. Available online: https://sites.google.com/site/smartappliancesproject/ontologies/reference-ontology (accessed on 15 May 2021).

85. Spoladore, D.; Mahroo, A.; Trombetta; Sacco, M. ComfOnt: A Semantic Framework for Indoor Comfort and Energy Saving in Smart Homes. Electronics 2019, 8, 1449. [CrossRef]

86. Compton, M.; Barnaghi, P.; Bermudez, L.; GarcÃa-Castro, R.; Corcho, O.; Cox, S.; Graybeal, J.; Hauswirth, M.; Henson, C.; Herzog, A.; et al. The SSN ontology of the W3C semantic sensor network incubator group. J. Web Semant. 2012, 17, 25-32. [CrossRef]

87. Wendel, J.; Simons, A.; Nichersu, A.; Murshed, S. Rapid development of semantic 3D city models for urban energy analysis based on free and open data sources and software. In Proceedings of the 3rd ACM SIGSPATIAL Workshop on Smart Cities and Urban Analytics, Redondo Beach, CA, USA, 7-10 November 2017. [CrossRef]

88. Rodríguez-Molina, J.; Martínez, J.F.; Castillejo, P.; De Diego, R. SMArc: A proposal for a smart, semantic middleware architecture focused on smart city energy management. Int. J. Distrib. Sens. Netw. 2013, 2013. [CrossRef]

89. Tang, Y.; Ciuciu, I. Semantic decision support models for energy efficiency in smart-metered homes. In Proceedings of the 2012 IEEE 11th International Conference on Trust, Security and Privacy in Computing and Communications, Liverpool, UK, 25-27 June 2012; pp. 1777-1784. [CrossRef]

90. Oprea, M.M. AIR_POLLUTION_Onto: An Ontology for Air Pollution Analysis and Control. In Artificial Intelligence Applications and Innovations III; Springer: Boston, MA, USA, 2009; pp. 135-143.

91. Metral, C.; Falquet, G.; Karatzas, K. Ontologies for the integration of air quality models and 3D city models. arXiv 2012, arXiv:1201.6511.

92. CityGML Website. Available online: https://www.ogc.org/standards/citygml (accessed on 15 May 2021).

93. Camporeale, C.; De Nicola, A.; Villani, M.L. Semantics-based Services for a Low Carbon Society: An Application on Emissions Trading System data and scenarios management. Environ. Model. Softw. 2015, 64, 124-142. [CrossRef]

94. Ahmedi, L.; Jajaga, E.; Ahmedi, F. An Ontology Framework for Water Quality Management. In Proceedings of the 6th International Conference on Semantic Sensor Networks, Sydney, Australia, 21-25 October 2013; pp. 35-50.

95. Howell, S.; Rezgui, Y.; Beach, T. Integrating building and urban semantics to empower smart water solutions. Autom. Constr. 2017, 81, 434-448. [CrossRef]

96. Du, H.; Dimitrova, V.; Magee, D.; Stirling, R.; Curioni, G.; Reeves, H.; Clarke, B.; Cohn, A. An ontology of soil properties and processes. In Proceedings of the International Semantic Web Conference, Kobe, Japan, 17-21 October 2016; pp. 30-37. 
97. $\mathrm{Hu}, \mathrm{X}$; Chen, Q.; Du, M. Ontology-based multi-sensor information integration model for urban gardens and green spaces. In IOP Conference Series: Earth and Environmental Science; IOP Publishing: Bristol, UK, 2020; Volume 615, p. 012023.

98. Cagliero, L.; Cerquitelli, T.; Chiusano, S.; Garza, P.; Ricupero, G.; Xiao, X. Modeling correlations among air pollution-related data through generalized association rules. In Proceedings of the 2016 IEEE International Conference on Smart Computing (SMARTCOMP), St. Louis, MO, USA, 18-20 May 2016; pp. 1-6.

99. Agrawal, R.; Srikant, R. Fast algorithms for mining association rules. In Proceedings of the 20th International Conference on Very Large Data Bases, Santiago de Chile, Chile, 12-15 September 1994; Volume 1215, pp. 487-499.

100. García-Díaz, J.A.; Noguera-Arnaldos, J.Á.; Hernández-Alcaraz, M.L.; Robles-Marín, I.M.; García-Sánchez, F.; Valencia-García, R. AllergyLESS. An Intelligent Recommender System to Reduce Exposition Time to Allergens in Smart-Cities. In Distributed Computing and Artificial Intelligence, 15th International Conference; De La Prieta, F., Omatu, S., Fernández-Caballero, A., Eds.; Springer International Publishing: Cham, Switzerland, 2019; pp. 61-68.

101. D2RQ Website. Available online: http:/ / d2rq.org (accessed on 15 May 2021).

102. Bizer, C.; Seaborne, A. D2RQ-treating non-RDF databases as virtual RDF graphs. In Proceedings of the 3rd International Semantic Web Conference (ISWC2004), Hiroshima, Japan, 7-11 November 2004.

103. Zgheib, R.; De Nicola, A.; Villani, M.L.; Conchon, E.; Bastide, R. A Flexible Architecture for Cognitive Sensing of Activities in Ambient Assisted Living. In Proceedings of the 2017 IEEE 26th International Conference on Enabling Technologies: Infrastructure for Collaborative Enterprises (WETICE), Poznan, Poland, 21-23 June 2017; pp. 284-289. [CrossRef]

104. Usman Sarwar, M.; Rehman Javed, A.; Kulsoom, F.; Khan, S.; Tariq, U.; Kashif Bashir, A. PARCIV: Recognizing physical activities having complex interclass variations using semantic data of smartphone. Softw. Pract. Exp. 2020. [CrossRef]

105. Fouquet, K.; Faraut, G.; Lesage, J.J. Life Habits Modeling with Stochastic Timed Automata in Ambient Assisted Living. IEEE Trans. Syst. Man Cybern. Syst. 2020, 2020, 2740-2745. [CrossRef]

106. Baldassini, D.; Colombo, V.; Spoladore, D.; Sacco, M.; Arlati, S. Customization of domestic environment and physical training supported by virtual reality and semantic technologies: A use-case. In Proceedings of the 2017 IEEE 3rd International Forum on Research and Technologies for Society and Industry (RTSI), Modena, Italy, 11-13 September 2017; pp. 1-6. [CrossRef]

107. Martínez-Santiago, F.; García-Viedma, M.; Williams, J.; Slater, L.; Gkoutos, G. Aging Neuro-Behavior Ontology. Appl. Ontol. 2020, 15, 219-239. [CrossRef]

108. Latfi, F.; Lefebvre, B.; Descheneaux, C. Ontology-Based Management of the Telehealth Smart Home, Dedicated to Elderly in Loss of Cognitive Autonomy. In Proceedings of the OWLED 2007 Workshop on OWL: Experiences and Directions, Innsbruck, Austria, 6-7 June 2007.

109. Bae, I.H. An Ontology-Based Approach to ADL Recognition in Smart Homes. Future Gener. Comput. Syst. 2014, $33,32-41$. [CrossRef]

110. Moreira, J.L.R.; Pires, L.; Sinderen, M.; Daniele, L.; Girod-Genet, M. SAREF4health: Towards IoT standard-based ontology-driven cardiac e-health systems. Appl. Ontol. 2020, 15, 385-410. [CrossRef]

111. Peng, C.; Goswami, P. Meaningful Integration of Data from Heterogeneous Health Services and Home Environment Based on Ontology. Sensors 2019, 19, 1747. [CrossRef]

112. CoSSN Ontology. Available online: https://data.mendeley.com/datasets/437rdzzfbd/1 (accessed on 15 May 2021).

113. ETSI Website. Available online: https://www.etsi.org/about (accessed on 15 May 2021).

114. Tiwari, S.; Abraham, A. Semantic assessment of smart healthcare ontology. Int. J. Web Inf. Syst. 2020, 16, 475-491. [CrossRef]

115. Rhayem, A.; Mhiri, M.; Gargouri, F. HealthIoT ontology for data semantic representation and interpretation obtained from medical connected objects. In Proceedings of the 2017 IEEE/ACS 14th International Conference on Computer Systems and Applications (AICCSA), Hammamet, Tunisia, 30 October-3 November 2017; pp. 1470-1477. [CrossRef]

116. Alirezaie, M.; Renoux, J.; Köckemann, U.; Kristoffersson, A.; Karlsson, L.; Blomqvist, E.; Tsiftes, N.; Voigt, T.; Loutfi, A. An Ontology-based Context-aware System for Smart Homes: E-care@home. Sensors 2017, 17, 1586. [CrossRef]

117. Riboni, D.; Bettini, C.; Civitarese, G.; Janjua, Z.H.; Helaoui, R. SmartFABER: Recognizing fine-grained abnormal behaviors for early detection of mild cognitive impairment. Artif. Intell. Med. 2016, 67, 57-74. [CrossRef]

118. Berat Sezer, O.; Can, S.Z.; Dogdu, E. Development of a smart home ontology and the implementation of a semantic sensor network simulator: An Internet of Things approach. In Proceedings of the 2015 International Conference on Collaboration Technologies and Systems (CTS), Atlanta, GA, USA, 1-5 June 2015; pp. 12-18. [CrossRef]

119. Gómez-Romero, J.; Serrano, M.A.; Patricio, M.A.; García, J.; Molina, J.M. Context-Based Scene Recognition from Visual Data in Smart Homes: An Information Fusion Approach. Pers. Ubiquitous Comput. 2012, 16, 835-857. [CrossRef]

120. Zhang, Y.; Tian, G.; Zhang, S.; Li, C. A Knowledge-Based Approach for Multiagent Collaboration in Smart Home: From Activity Recognition to Guidance Service. IEEE Trans. Instrum. Meas. 2020, 69, 317-329. [CrossRef]

121. Ye, J.; Stevenson, G.; Dobson, S. KCAR: A knowledge-driven approach for concurrent activity recognition. Pervasive Mob. Comput. 2015, 19, 47-70. [CrossRef]

122. Noor, M.M.; Salcic, Z.; Wang, K. Ontology-based sensor fusion activity recognition. J. Ambient. Intell. Humaniz. Comput. 2020, 11, 3073-3087. [CrossRef]

123. Stavropoulos, T.G.; Vrakas, D.; Vlachava, D.; Bassiliades, N. BOnSAI: A Smart Building Ontology for Ambient Intelligence. In Proceedings of the 2nd International Conference on Web Intelligence, Mining and Semantics (WIMS '12), Craiova, Romania, 6-8 June 2012. [CrossRef] 
124. Balaji, B.; Bhattacharya, A.; Fierro, G.; Gao, J.; Gluck, J.; Hong, D.; Johansen, A.; Koh, J.; Ploennigs, J.; Agarwal, Y.; et al. Brick: Metadata schema for portable smart building applications. Appl. Energy 2018, 226, 1273-1292. [CrossRef]

125. Kofler, M.J.; Reinisch, C.; Kastner, W. A semantic representation of energy-related information in future smart homes. Energy Build. 2012, 47, 169-179. [CrossRef]

126. Tao, M.; Zuo, J.; Liu, Z.; Castiglione, A.; Palmieri, F. Multi-layer cloud architectural model and ontology-based security service framework for IoT-based smart homes. Future Gener. Comput. Syst. 2018, 78, 1040-1051. [CrossRef]

127. Ni, Q.; Pau, I.; García Hernando, A. A foundational ontology-based model for human activity representation in smart homes. J. Ambient. Intell. Smart Environ. 2016, 8, 47-61. [CrossRef]

128. Civitarese, G.; Sztyler, T.; Riboni, D.; Bettini, C.; Stuckenschmidt, H. POLARIS: Probabilistic and ontological activity recognition in smart-homes. IEEE Trans. Knowl. Data Eng. 2021, 33, 209-223. [CrossRef]

129. Alsukhayri, A.; Aslam, M.; Saeedi, K.; Malik, M. A linked open data-oriented sustainable system for transparency and open access to government data: A case study of the public's response to women's driving in Saudi Arabia. Sustainability 2020, $12,8608$. [CrossRef]

130. Porwol, L.; Ojo, A.; Breslin, J.G. An ontology for next generation e-Participation initiatives. Gov. Inf. Q. 2016, 33, 583-594. [CrossRef]

131. Bellini, P.; Nesi, P.; Paolucci, M.; Zaza, I. Smart City Architecture for Data Ingestion and Analytics: Processes and Solutions. In Proceedings of the 2018 IEEE Fourth International Conference on Big Data Computing Service and Applications (BigDataService), Bamberg, Germany, 26-29 March 2018; pp. 137-144. [CrossRef]

132. Ardito, C.; Caivano, D.; Colizzi, L.; Verardi, L. BPMN Extensions and Semantic Annotation in Public Administration Service Design. In Lecture Notes in Computer Science (Including Subseries Lecture Notes in Artificial Intelligence and Lecture Notes in Bioinformatics); Springer International Publishing: Cham, Switzerland, 2020; Volume 12481 LNCS, pp. 118-129. [CrossRef]

133. Muñoz-Soro, J.; EstebAn, G.; Corcho, O.; Serón, F. PPROC, an ontology for transparency in public procurement. Semant. Web 2016, 7, 295-309. [CrossRef]

134. Younsi Dahbi, K.; Lamharhar, H.; Chiadmi, D. Towards a knowledge graph for open healthcare data. Int. J. Adv. Trends Comput. Sci. Eng. 2020, 9, 5654-5662. [CrossRef]

135. Bianchini, D.; De Antonellis, V.; Garda, M.; Melchiori, M. Exploiting Smart City Ontology and Citizens' Profiles for Urban Data Exploration. In Lecture Notes in Computer Science (Including Subseries Lecture Notes in Artificial Intelligence and Lecture Notes in Bioinformatics); Springer International Publishing: Cham, Switzerland, 2018; Volume 11229 LNCS, pp. 372-389. [CrossRef]

136. Ardito, C.; Caivano, D.; Colizzi, L.; Verardi, L. Towards a model to address the interplay between IoT applications and users in complex heterogeneous contexts. In Lecture Notes in Computer Science (Including Subseries Lecture Notes in Artificial Intelligence and Lecture Notes in Bioinformatics); Springer International Publishing: Cham, Switzerland, 2019; Volume 11262 LNCS, pp. $283-293$. [CrossRef]

137. Consoli, S.; Mongiovic, M.; Nuzzolese, A.G.; Peroni, S.; Presutti, V.; Reforgiato Recupero, D.; Spampinato, D. A Smart City Data Model Based on Semantics Best Practice and Principles. In Proceedings of the 24th International Conference on World Wide Web, WWW '15 Companion, Florence, Italy, 18-22 May 2015; pp. 1395-1400. [CrossRef]

138. Ullah, F.; Qayyum, S.; Thaheem, M.J.; Al-Turjman, F.; Sepasgozar, S.M. Risk management in sustainable smart cities governance: A TOE framework. Technol. Forecast. Soc. Chang. 2021, 167, 120743. [CrossRef]

139. Provitolo, D.; Müller, J.P.; Dubos-Paillard, E. Validation of an ontology of risk and disaster through a case study of the 1923 Great Kanto Earthquake. In Proceedings of the 3rd International Conference on Complex Systems and Applications, Le Havre, France, 29 June-2 July, 2009.

140. Coletti, A.; De Nicola, A.; Villani, M.L. Building Climate Change into Risk Assessments. Nat. Hazards 2016, 84, 1307-1325. [CrossRef]

141. Coletti, A.; De Nicola, A.; Di Pietro, A.; La Porta, L.; Pollino, M.; Rosato, V.; Vicoli, G.; Villani, M.L. A Comprehensive System for Semantic Spatiotemporal Assessment of Risk in Urban Areas. J. Contingencies Crisis Manag. 2020, 28, 178-193. [CrossRef]

142. Mohammad, M.A.; Kaloskampis, I.; Hicks, Y.; Setchi, R. Ontology-based Framework for Risk Assessment in Road Scenes Using Videos. Procedia Comput. Sci. 2015, 60, 1532-1541. [CrossRef]

143. Meng, X.; Wang, F.; Xie, Y.; Song, G.; Ma, S.; Hu, S.; Bai, J.; Yang, Y. An Ontology-Driven Approach for Integrating Intelligence to Manage Human and Ecological Health Risks in the Geospatial Sensor Web. Sensors 2018, 18, 3619. [CrossRef]

144. Sales, T.P.; Baião, F.; Guizzardi, G.; Almeida, J.P.A.; Guarino, N.; Mylopoulos, J. The Common Ontology of Value and Risk. In Conceptual Modeling; Trujillo, J.C., Davis, K.C., Du, X., Li, Z., Ling, T.W., Li, G., Lee, M.L., Eds.; Springer International Publishing: Cham, Switzerland, 2018; pp. 121-135.

145. Yang, Q.; Zuo, C.; Liu, X.; Yang, Z.; Zhou, H. Risk Response for Municipal Solid Waste Crisis Using Ontology-Based Reasoning. Int. J. Environ. Res. Public Health 2020, 17, 3312. [CrossRef]

146. Sirin, E.; Parsia, B.; Grau, B.C.; Kalyanpur, A.; Katz, Y. Pellet: A practical owl-dl reasoner. J. Web Semant. 2007, 5, 51-53. [CrossRef]

147. Musen, M.A. The protégé project: A look back and a look forward. AI Matters 2015, 1, 4-12. [CrossRef]

148. Wu, Z.; Shen, Y.; Wang, H.; Wu, M. Urban Flood Disaster Risk Evaluation Based on Ontology and Bayesian Network. J. Hydrol. 2020, 583, 124596. [CrossRef] 
149. Coletti, A.; De Nicola, A.; Vicoli, G.; Villani, M.L. Semantic Modeling of Cascading Risks in Interoperable Socio-technical Systems. In Enterprise Interoperability VIII; Popplewell, K., Thoben, K.D., Knothe, T., Poler, R., Eds.; Springer International Publishing: Cham, Switzerland, 2019; pp. 119-129.

150. Yu, F.; Fan, B.; Li, X. Improving emergency preparedness to cascading disasters: A case-driven risk ontology modelling. J. Contingencies Crisis Manag. 2020, 28, 194-214. [CrossRef]

151. Wei, L.; Du, H.; Mahesar, Q.A.; Al Ammari, K.; Magee, D.; Clarke, B.; Dimitrova, V.; Gunn, D.; Entwisle, D.; Reeves, H.; Cohn, A. A decision support system for urban infrastructure inter-asset management employing domain ontologies and qualitative uncertainty-based reasoning. Expert Syst. Appl. 2020, 158. [CrossRef]

152. Schwee, J.; Sangogboye, F.; Johansen, A.; Kjærgaard, M. Ontology-based modeling of privacy vulnerabilities for data sharing. IFIP Adv. Inf. Commun. Technol. 2020, 576 LNCS, 109-125. [CrossRef]

153. Fernández, J.; Sabou, M.; Kirrane, S.; Kiesling, E.; Ekaputra, F.; Azzam, A.; Wenning, R. User consent modeling for ensuring transparency and compliance in smart cities. Pers. Ubiquitous Comput. 2020, 24, 465-486. [CrossRef]

154. Gonzalez-Gil, P.; Martinez, J.A.; Skarmeta, A.F. Lightweight Data-Security Ontology for IoT. Sensors 2020, 20, 801. [CrossRef]

155. Gyrard, A.; Bonnet, C.; Boudaoud, K. An Ontology-Based Approach for Helping to Secure the ETSI Machine-to-Machine Architecture. In Proceedings of the 2014 IEEE International Conference on Internet of Things (iThings), and IEEE Green Computing and Communications (GreenCom) and IEEE Cyber, Physical and Social Computing (CPSCom), Taipei, Taiwan, 1-3 September 2014; pp. 109-116. [CrossRef]

156. Gonzalez-Gil, P.; Skarmeta, A.F.; Martinez, J.A. Towards an Ontology for IoT Context-Based Security Evaluation. In Proceedings of the 2019 Global IoT Summit (GIoTS), Aarhus, Denmark, 17-21 June 2019; pp. 1-6. [CrossRef]

157. Arruda, M.F.; Bulcão Neto, R.F. Toward a Lightweight Ontology for Privacy Protection in IoT. In Proceedings of the 34th ACM/SIGAPP Symposium on Applied Computing (SAC '19), Limassol, Cyprus, 8-12 April 2019; pp. 880-888. [CrossRef]

158. Joshi, K.P.; Banerjee, A. Automating Privacy Compliance Using Policy Integrated Blockchain. Cryptography 2019, 3, 7. [CrossRef]

159. Androulaki, E.; Barger, A.; Bortnikov, V.; Cachin, C.; Christidis, K.; De Caro, A.; Enyeart, D.; Ferris, C.; Laventman, G.; Manevich, Y.; et al. Hyperledger fabric: A distributed operating system for permissioned blockchains. In Proceedings of the Thirteenth EuroSys Conference, Porto, Portugal, 23-26 April, 2018; pp. 1-15.

160. Panori, A.; Kakderi, C.; Tsarchopoulos, P. Designing the Ontology of a Smart City Application for Measuring Multidimensional Urban Poverty. J. Knowl. Econ. 2019, 10, 921-940. [CrossRef]

161. Nasim, Z.; Khan, I. Solving Poverty using Ontology. In Proceedings of the 10th International Conference on Knowledge Engineering and Ontology Development, Seville, Spain, 18-20 September 2018; pp. 271-278. [CrossRef]

162. Fernandez, M.; Alani, H. Contextual Semantics for Radicalisation Detection on Twitter. In Proceedings of the Semantic Web for Social Good Workshop (SW4SG) at International Semantic Web Conference, Monterey, CA, USA, 9 October 2018.

163. Barhamgi, M.; Lara-Cabrera, R.; Benslimane, D.; Camacho, D. Ontology Uses for Radicalisation Detection on Social Networks. In Intelligent Data Engineering and Automated Learnin -IDEAL 2018; Yin, H., Camacho, D., Novais, P., Tallón-Ballesteros, A.J., Eds.; Springer International Publishing: Cham, Switzerland, 2018; pp. 3-8.

164. De Nicola, A.; D'Agostino, G. Assessment of Gender Divide in Scientific Communities. Scientometrics 2021. [CrossRef]

165. Rahman, M.A.; Hossain, M.S.; Hassanain, E.; Muhammad, G. Semantic Multimedia Fog Computing and IoT Environment: Sustainability Perspective. IEEE Commun. Mag. 2018, 56, 80-87. [CrossRef]

166. Schwarz, J.S.; Witt, T.; Nieße, A.; Geldermann, J.; Lehnhoff, S.; Sonnenschein, M. Towards an Integrated Development and Sustainability Evaluation of Energy Scenarios Assisted by Automated Information Exchange. In Smart Cities, Green Technologies, and Intelligent Transport Systems; Donnellan, B., Klein, C., Helfert, M., Gusikhin, O., Pascoal, A., Eds.; Springer International Publishing: Cham, Switzerland, 2019; pp. 3-26.

167. Massaro, E.; Athanassiadis, A.; Psyllidis, A.; Binder, C. Ontology-Based Integration of Urban Sustainability Indicators. In Sustainability Assessments of Urban Systems; Cambridge University Press: Cambridge, UK, 2020; pp. 332-350. [CrossRef]

168. Kuster, C.; Hippolyte, J.L.; Rezgui, Y. The UDSA ontology: An ontology to support real time urban sustainability assessment. Adv. Eng. Softw. 2020, 140, 102731. [CrossRef]

169. Konys, A. An Ontology-Based Knowledge Modelling for a Sustainability Assessment Domain. Sustainability 2018, 10, 300. [CrossRef]

170. Sosunova, I.; Zaslavsky, A.; Anagnostopoulos, T.; Fedchenkov, P.; Sadov, O.; Medvedev, A. SWM-PnR: Ontology-based contextdriven knowledge representation for IoT-enabled waste management. In Lecture Notes in Computer Science (Including Subseries Lecture Notes in Artificial Intelligence and Lecture Notes in Bioinformatics); Springer: Cham, Switzerland, 2017; Volume 10531 LNCS, pp. 151-162. [CrossRef]

171. Stratigea, A.; Panagiotopoulou, M.; Kokla, M. Conceptualizing Small and Medium-Sized Smart Cities in the Mediterranean Region: An Ontological Approach. Int. J. E-Plan. Res. 2019, 8, 17-41. [CrossRef]

172. Hellmund, T.; Hertweck, P.; Hilbring, D.; Mossgraber, J.; Alexandrakis, G.; Pouli, P.; Siatou, A.; Padeletti, G. Introducing the HERACLES Ontology—Semantics for Cultural Heritage Management. Heritage 2018, 1, 26. [CrossRef]

173. De Nicola, A.; Giovinazzi, S.; Guarascio, M.; Rizzi, P; Villani, M.L. Gamified Decision Making for a Participatory Post-Crisis Recovery: A Model Based Process. In Proceedings of the 30th European Safety and Reliability Conference-ESREL 2020, Venice, Italy, 1-6 November 2020. [CrossRef] 
174. Qi, J.; Ding, L.; Lim, S. Ontology-based knowledge representation of urban heat island mitigation strategies. Sustain. Cities Soc. 2020, 52, 101875. [CrossRef]

175. Rocha, B.; Silva, L.; Batista, T.; Cavalcante, E.; Gomes, P. An Ontology-based Information Model for Multi-Domain Semantic Modeling and Analysis of Smart City Data. In Proceedings of the Brazilian Symposium on Multimedia and the Web, São Luís, Brazil, 30 November-4 December 2020; pp. 73-80. [CrossRef]

176. Brutti, A.; De Sabbata, P.; Frascella, A.; Gessa, N.; Ianniello, R.; Novelli, C.; Pizzuti, S.; Ponti, G. Smart City Platform Specification: A Modular Approach to Achieve Interoperability in Smart Cities. In The Internet of Things for Smart Urban Ecosystems; Cicirelli, F., Guerrieri, A., Mastroianni, C., Spezzano, G., Vinci, A., Eds.; Springer International Publishing: Cham, Switzerland, 2019; pp. 25-50.

177. Chinnici, M.; Ponti, G.; Santomauro, G. Smart City Platform: Scalability, Interoperability and Replicability Platform to Manage Urban Applications. In Sensors and Microsystems; Di Francia, G., Di Natale, C., Eds.; Lecture Notes in Electrical Engineering; Springer International Publishing: Cham, Switzerland, 2021; pp. 1-7.

178. Sobral, T.; Galvão, T.; Borges, J. Knowledge-Assisted Visualization of Multi-Level Origin-Destination Flows Using Ontologies. IEEE Trans. Intell. Transp. Syst. 2021. [CrossRef]

179. Swarnamugi, M.; Chinnaiyan, R. Context-Aware Smart Reliable Service Model for Intelligent Transportation System Based on Ontology. In Proceedings of ICRIC 2019; Singh, P.K., Kar, A.K., Singh, Y., Kolekar, M.H., Tanwar, S., Eds.; Springer International Publishing: Cham, Switzerland, 2020; pp. 23-30.

180. Colace, F.; De Santo, M.; Lombardi, M.; Pascale, F.; Santaniello, D.; Tucker, A. A Multilevel Graph Approach for Predicting Bicycle Usage in London Area. In Fourth International Congress on Information and Communication Technology; Yang, X.S., Sherratt, S., Dey, N., Joshi, A., Eds.; Springer: Singapore, 2020; pp. 353-362.

181. Fernandez, S.; Hadfi, R.; Ito, T.; Marsa-Maestre, I.; Velasco, J.R. Ontology-Based Architecture for Intelligent Transportation Systems Using a Traffic Sensor Network. Sensors 2016, 16, 1287. [CrossRef]

182. Barbancho, J.; Ropero, J.; Luque, J.; Caraballo, A.; León, C. Social Parking: Applying the Citizens as Sensors Paradigm to Parking Guidance and Information. Sustainability 2019, 11, 6549. [CrossRef]

183. Sotres, P.; Lanza, J.; Sánchez, L.; Santana, J.R.; López, C.; Muñoz, L. Breaking Vendors and City Locks through a Semantic-enabled Global Interoperable Internet-of-Things System: A Smart Parking Case. Sensors 2019, 19, 229. [CrossRef]

184. Viktorović, M.; Yang, D.; Vries, B.D. Connected Traffic Data Ontology (CTDO) for Intelligent Urban Traffic Systems Focused on Connected (Semi) Autonomous Vehicles. Sensors 2020, 20, 2961. [CrossRef]

185. Janowicz, K.; Haller, A.; Cox, S.J.; Le Phuoc, D.; Lefrançois, M. SOSA: A lightweight ontology for sensors, observations, samples, and actuators. J. Web Semant. 2019, 56, 1-10. [CrossRef]

186. Gröger, G.; Plümer, L. CityGML-Interoperable semantic 3D city models. ISPRS J. Photogramm. Remote Sens. 2012, 71, 12-33. [CrossRef]

187. Espinoza-Arias, P.; Poveda-Villalón, M.; García-Castro, R.; Corcho, O. Ontological Representation of Smart City Data: From Devices to Cities. Appl. Sci. 2019, 9, 32. [CrossRef]

188. Ju, J.; Liu, L.; Feng, Y. Citizen-centered big data analysis-driven governance intelligence framework for smart cities. Telecommun. Policy 2018, 42, 881-896.

189. Troncy, R.; Rizzo, G.; Jameson, A.; Corcho, O.; Plu, J.; Palumbo, E.; Ballesteros Hermida, J.C.; Spirescu, A.; Kuhn, K.D.; Barbu, C.; et al. 3cixty: Building comprehensive knowledge bases for city exploration. J. Web Semant. 2017, 46-47, 2-13. [CrossRef]

190. Juric, R.; Madland, O. Semantic Framework for Creating an Instance of the IoE in Urban Transport: A Study of Traffic Management with Driverless Vehicles. In Proceedings of the 2020 IEEE International Conference on Human-Machine Systems (ICHMS), Rome, Italy, 7-9 September 2020; pp. 1-8. [CrossRef]

191. D’Aniello, G.; Gaeta, M.; Orciuoli, F.; Sansonetti, G.; Sorgente, F. Knowledge-based smart city service system. Electronics 2020, 9, 965. [CrossRef]

192. The Event Ontology. Available online: http://motools.sourceforge.net/event/event.html (accessed on 15 May 2021 ). 